Document downloaded from:

http://hdl.handle.net/10251/139657

This paper must be cited as:

Rotunno, T.; Fagone, M.; Bertolesi, E.; Grande, E.; Milani, G. (15-0). Single lap shear tests of masonry curved pillars externally strengthened by CFRP strips. Composite Structures. 200:434-448. https://doi.org/10.1016/j.compstruct.2018.05.097

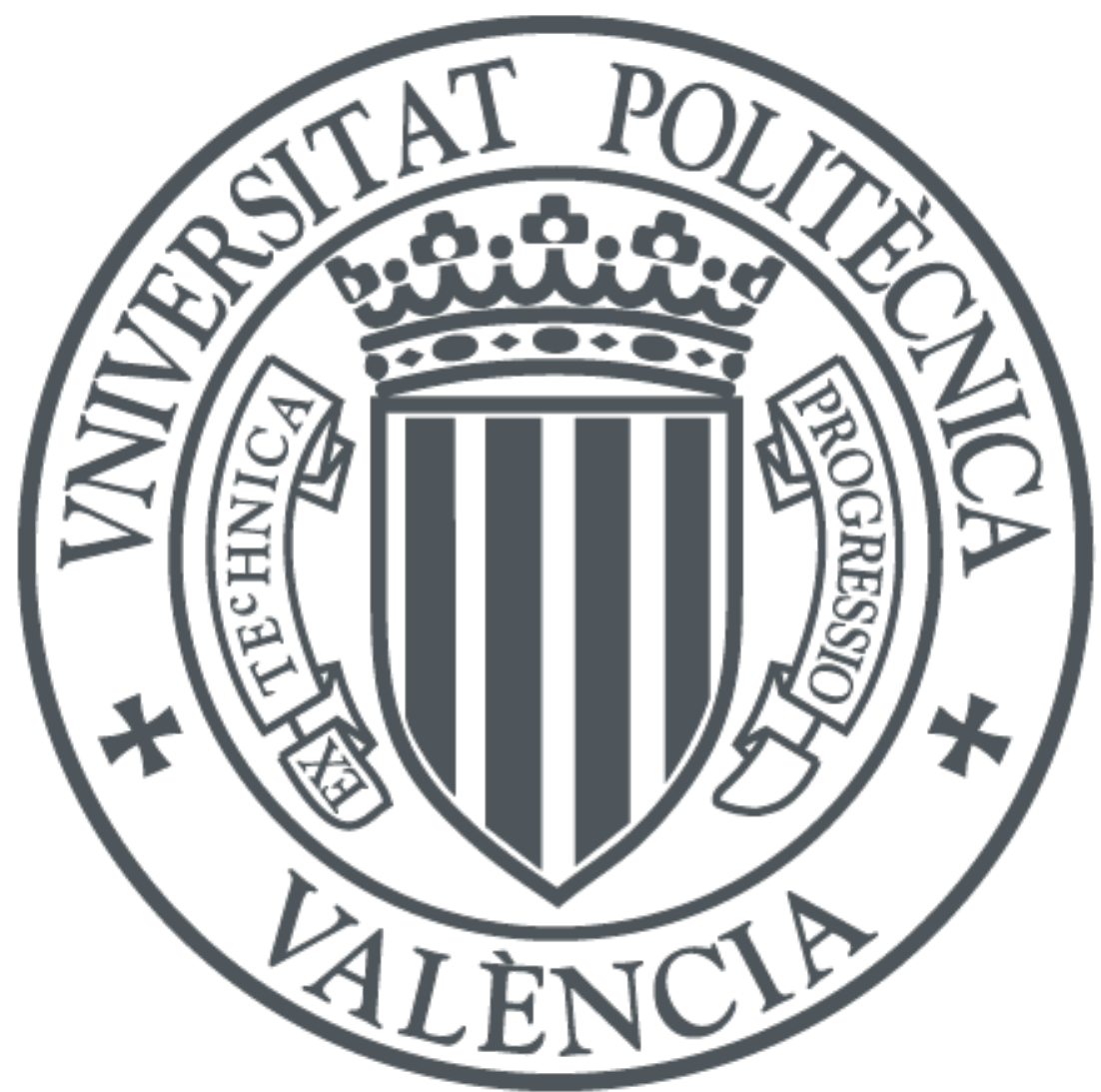

The final publication is available at

https://doi.org/10.1016/j.compstruct.2018.05.097

Copyright Elsevier

Additional Information 


\title{
Single lap shear tests of masonry curved pillars externally strengthened by CFRP strips
}

\author{
Tommaso ROTUNNO ${ }^{(1)}$, Mario FAGONE ${ }^{(2)}$, Elisa BERTOLESI ${ }^{(3)}$, Ernesto GRANDE ${ }^{(4)}$, Gabriele \\ MILANI $^{*}(5)$
}

(1) Dipartimento di Architettura (DiDA), Università degli Studi di Firenze, Piazza Brunelleschi 6, 50121 Florence (Italy)

(2) Dipartimento di Ingegneria Civile e Ambientale (DICA), Università degli Studi di Firenze, Piazza Brunelleschi 6, 50121 Florence (Italy)

(3) ICITECH, Universitat Politècnica de Valencia, Camino de Vera s/n 46022, Valencia (Spain)

(4) Department of Sustainability Engineering, University Guglielmo Marconi, Via Plinio 44, 00193 Rome (Italy)

(5) Department of Architecture, Built environment and Construction engineering (ABC), Politecnico di Milano, Piazza Leonardo da Vinci 32, 20133, Milan (Italy)

* $\quad$ corresponding author, e-mail: gabriele.milani@polimi.it

\begin{abstract}
The paper presents an experimental study concerning the bond behaviour of Carbon Fiber Reinforced Polymers (CFRP) sheet reinforcements applied to curved masonry surfaces. Such strengthening technique is more and more used in structural rehabilitation and retrofitting of existing buildings. Its effectiveness has been demonstrated by several studies published in the literature, mostly devoted to flat bonded surfaces. Seeing that CFRP are extensively applied on arches and vaults but only few research activities concern curved bonded surfaces, the experimental study described in this paper is aimed to contribute to fill this gap. The experimental program was carried out on portions of masonry arches, reinforced by CFRP sheets bonded at extrados or intrados, tested by a single lap shear test. The experimental results allowed to analyse the effectiveness of such reinforcements, loaded by actions tangent to an end of the reinforcement itself, with respect to its position (intrados or extrados) and to the curvature of the bonding surface. As expected, the results highlight that the bond behaviour strongly depend on the position of the reinforcement. In particular, the capacity of reinforcements bonded at the extrados increases with the curvature, while decreases with the curvature for those bonded at intrados.
\end{abstract}

Keywords: masonry; masonry arch; CFRP reinforcements; delamination; curvature effect.

\section{Nomenclature}

$\mathrm{P} \quad$ representative point in the diagrams reported in Figure 11 and Figure 12.

$\mathrm{P}_{\mathrm{f}} \quad$ first crack point (Figure 11 and Figure 12)

$\mathrm{P}_{1} \quad$ first peak point (Figure 11 and Figure 12)

$\mathrm{P}_{\text {Fmax }} \quad$ maximum load point (Figure 11 and Figure 12) 


$\begin{array}{ll}\mathrm{P}_{\mathrm{U}} & \text { ultimate point (Figure } 11 \text { and Figure 12) } \\ \mathrm{F} & \text { load } \\ \mathrm{F}_{\mathrm{Pf}} & \text { first crack load } \\ \mathrm{F}_{\mathrm{P} 1} & \text { first peak load ( } \\ \mathrm{F}_{\mathrm{max}} & \text { maximum load } \\ \mathrm{F}_{\mathrm{U}} & \text { ultimate load } \\ u & \text { displacement (Figure 11 and Figure 12) } \\ \mathrm{u}_{\mathrm{Pf}} & \text { displacement at first crack (Figure 11 and Figure 12) } \\ \mathrm{u}_{\mathrm{P} 1} & \text { displacement at first peak (Figure 11 and Figure 12) } \\ \mathrm{u}_{\mathrm{Fmax}} & \text { displacement at maximum load (Figure 11 and Figure 12) } \\ \mathrm{u}_{\mathrm{U}} & \text { displacement at ultimate load (Figure 11 and Figure 12) } \\ s & \text { slip (Omega measurements, Figure 15) } \\ \bar{s} & \quad \text { estimated slip (Figure 16) } \\ \mathrm{K}_{0} & \text { initial slope of diagrams in Figure 11 } \\ \mathrm{K}_{0 \Omega} & \text { initial slope of diagrams in Figure 15 } \\ \mathrm{C} . \mathrm{V} . & \text { coefficient of variation }\end{array}$

\section{Introduction}

The practice of reinforcing and retrofitting interventions on masonry structures based on bonding composite materials is nowadays widely used in the professional environment and studied in the scientific field. The excellent mechanical performance of such reinforcements, combined with lightness and easiness of application, justify the interest of the technical and scientific communities on the use of these materials in the structural field. As demonstrated by several experimental investigations, externally bonded (EB) fiberreinforced composites, and particularly Carbon Fibers Reinforced Polymers (CFRP) sheets, can be effectively used to improve the structural behaviour of different masonry structural typologies. In fact such reinforcements, properly bonded to masonry walls, are able to improve both shear behavior, due to in-plane loads [1-4], and the bending one, related to out-of-plane actions [5-9]. CFRP sheets are, in fact, able to bear tensile stresses occurring in the masonry elements thanks to their adhesion to the substrate. The adhesion plays a crucial role in the effectiveness of the reinforcements. In particular, only a good bond strength between the CFRP sheets and the masonry substrate ensures the effectiveness of the reinforcement and moves the failure mechanism from the bonding surface to the masonry substrate. Many experimental analyses demonstrated that failure of such reinforcements, bonded to plane surfaces and loaded by in-plane actions, generally occurs in the substrate, a few millimetres below the bonding surface. For this reason, the load bearing capacity strongly depends on the mechanical properties of the substrate, as well as other parameters like the brickwork and the sheet geometric characteristics. As is known, tensile forces in the reinforcement are transferred to the substrate mainly through shear stresses, mostly concentrated in a limited portion of the reinforcement whose length is called "effective bond length" [10-18]. The failure load of a 
reinforcement strip increases with the bonding length until it reaches such a limit length; longer bonding lengths do not significantly increase the peak load. CFRP sheet reinforcements bonded to masonry generally exhibit brittle failure mode, occurring at a load level lower than the load bearing capacity of the carbon fiber fabric. Such brittle behaviour should be prevented in structural interventions. This can be done using different techniques, for example applying spike anchors that are able to increase both the load bearing capacity and the ductility of the reinforcement [19-22].

The widespread use of curved masonry structural elements (arches, vaults) in the architectonical heritage justifies the great interest of the technical and scientific community on the study of these structural typologies. Many research activities published in the literature are devoted to the analysis of the effectiveness of CFRP reinforcements applied to masonry arches (or vaults) [23-25]. Such reinforcements can modify the classical collapse mechanisms of arches (due to the opening of four hinges or five in symmetrical arches), avoiding hinges-type mechanisms to occur [26-28].

The effectiveness of CFRP reinforcements and the typical failure modes occurring in reinforced arches depend on the characteristics of the substrate and of the reinforcement itself, on the geometric distribution of the reinforcement itself and, obviously, on the adhesion as previously pointed out. The geometric distribution of the reinforcement is very important. For example, CFRP reinforcements can be bonded both continuously and discontinuously. Discontinuous reinforcements are used when hinges position is known in advance. Excluding detachment of the reinforcement, discontinuous CFRP sheets modify the position of hinges increasing the ultimate load. Continuous reinforcements, applied at intrados or extrados, produce collapse due to the detachment of the sheet and crushing of masonry. Continuous reinforcements bonded at the extrados are generally more effective because of peeling phenomenon being excluded [29-32]. Concerning the analysis of the sheet-to-substrate adhesion in the case of curved bonding surfaces, only a few research activities are presented in the literature [33-35], despite the great interest of the technical and scientific community on the use of CFRP sheets as reinforcement of masonry arches or vaults [36-39], In fact, differently from flat bonding surfaces, the adhesion properties of CFRP reinforcements can be strongly modified by peeling or confining effects occurring respectively if it is bonded at the intrados or at the extrados.

The experimental program described in this paper represent a contribution in this field. In particular, it concerns specimens representing a portion of masonry arches having different curvatures, reinforced at the intrados or at the extrados, loaded by actions tangent to an end of the reinforcement itself according to the so called Near End Supported Single Shear Test.

The paper layout is the following: the experimental program is described in the next section as well as the mechanical properties of the materials used, the procedure followed to manufacture the specimens and the test setup; the experimental results are reported in section 3 and final remarks conclude the paper.

\section{Experimental Program: materials, specimens and test setup}

The experimental program presented in this paper is aimed at investigating the effect of the geometry curvature of the bonding surface on the bond behaviour of CFRP sheet reinforcements externally applied to curved masonry pillars. This effect is analysed by performing single lap shear tests on specimens characterized by two different values of the internal radius $\mathrm{R}(\mathrm{R}=1500 \mathrm{~mm} ; \mathrm{R}=3000 \mathrm{~mm})$ together with two different strengthening configurations (reinforcement arranged at the intrados; reinforcement arranged at the extrados), as shown in Figure 1.

In the following sections a detailed description of the main material properties, the specimens configuration and of the test setup is reported. 

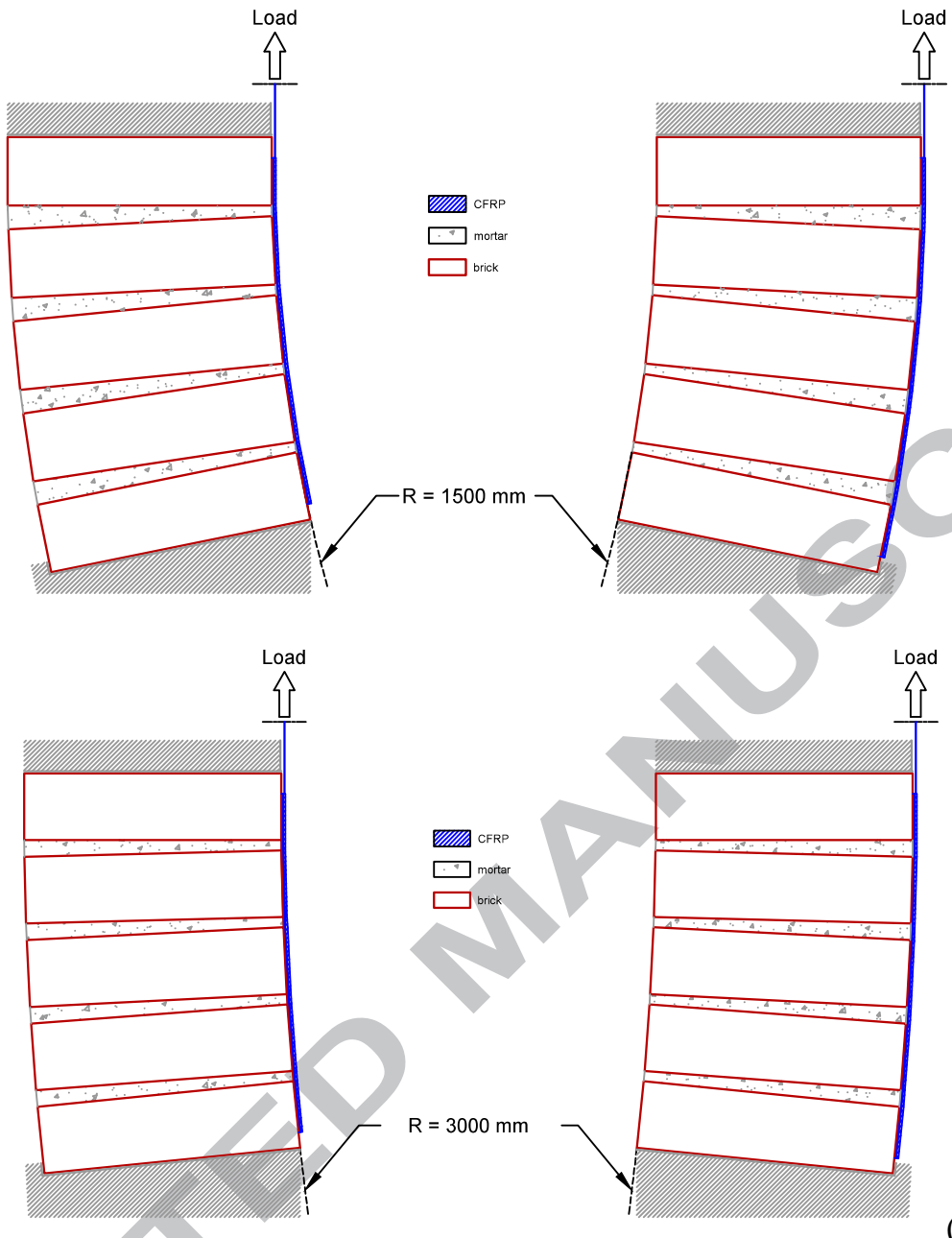

(a)

(b)

Figure 1: Experimental test scheme: (a) CA-I-0 and CA-E-0 series; (b) CB-I-0 and CB-E-0 series

\subsection{Materials characterization}

Before performing shear lap tests, the characterization of some of the materials composing the specimens was also performed.

The materials employed in the experimental program described in this paper are the same as those used in [19-21]. The reader can refer to these papers for a comprehensive description of the tests performed to characterize the mechanical properties of the materials. Here, just the main mechanical parameters and characteristics are summarized for the sake of completeness.

\subsubsection{Bricks}

Soft mud fired bricks, also called solid pressed bricks, with dimensions $250 \times 120 \times 65 \mathrm{~mm}$ were used for manufacturing the specimens. Pressed bricks were preferred to drawn bricks because their material structure (and, consequently, the anisotropy of mechanical properties and the quality of fracture path) resembles the one of traditional soft pressed bricks, that are used in most existing buildings [28]. Of course, the mechanical characteristics of traditional bricks could be different from that of the bricks here employed. Therefore, attention should be payed in the generalization of the results of the present experimental study since the 
Revised version highlighted: Green reviewer \#1, Yellow reviewer \#2

mechanical behavior of the reinforcement strongly depend on characteristics of the substrate. This is related to the failure mode that, as it will be described in the following, generally involve the substrate.

In order to evaluate the mechanical properties of the bricks, twelve of them were randomly chosen from the supply employed to manufacture the masonry specimens. Six of them were used for compression tests and six were used to determine the tensile strength. In particular, from each of the six bricks devoted to compression tests, four cubic specimens $50 \times 50 \times 50 \mathrm{~mm}$ and one prismatic specimen $50 \times 50 \times 150 \mathrm{~mm}$ were cut according to the scheme reported in Figure 2. Three of the four cubic specimens were tested in compression respectively according to the length (y), width (x) and thickness ( $\mathrm{z})$ of the brick. The loaddisplacement (i.e. relative displacement between the loaded faces of the specimen) diagrams obtained from such tests are reported in Figure 3.

The $50 \times 50 \times 150 \mathrm{~mm}$ prismatic specimens (Figure 2) were used for the determination of the elastic modulus. Omega displacement transducers applied on the lateral faces of the prisms, in the central portion, recorded relative displacements successively used for the computation of the elastic modulus. In each test, three compression cycles were performed, according to the y direction (see Figure 2), up to a half of the expected maximum load, evaluated according to the compressive tests carried out on the cubic specimens. For each specimen, three values of the elastic modulus were determined from the slope of the unloading branches, within the linear elastic range of the material, and, successively averaged.

From each of the others six bricks, a prismatic specimen $40 \times 40 \times 200 \mathrm{~mm}$ was obtained, with the main dimension parallel to the brick length (y). Three-point bending tests were performed on these specimens (see Figure 4 , span $=160 \mathrm{~mm}$ ). From one of the two halves of the specimen resulting from the bending test, a specimen was obtained for a direct tensile test: to this end, the fractured surface was regularized as to obtain a smaller specimen $(40 \times 40 \times 90 \mathrm{~mm})$. The tensile test was carried out after gluing the smaller surfaces of the specimen to steel plates adequately connected to the loading machine.

The results of the tests carried out on brick specimens are summarized in Table 1.
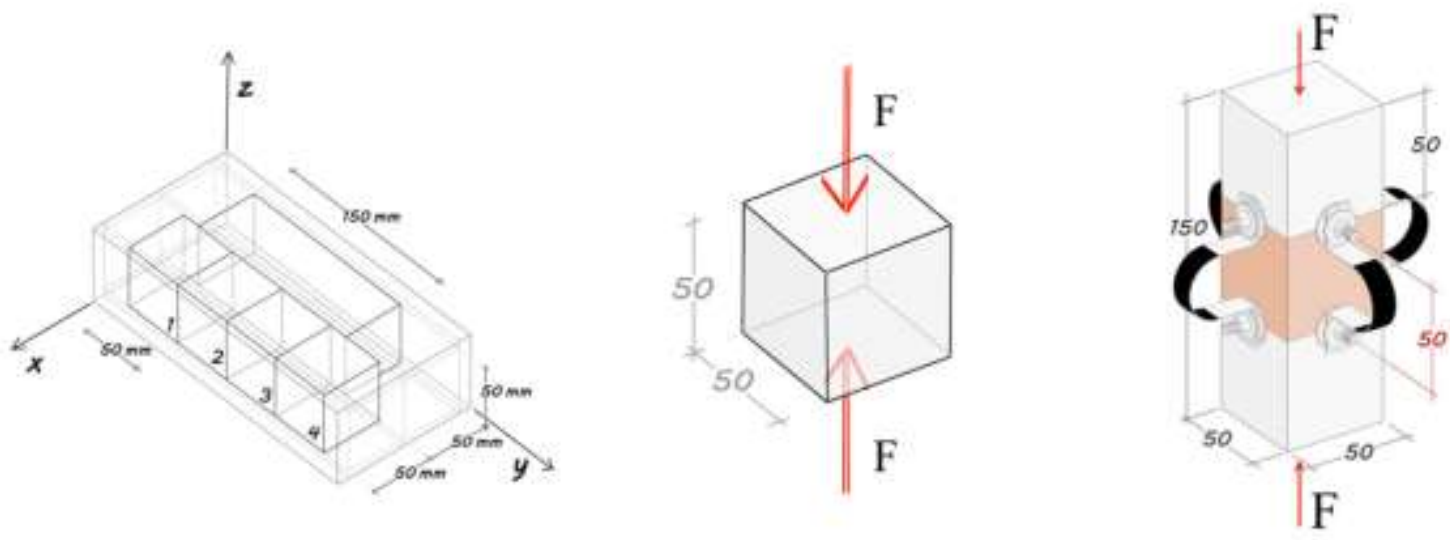

Figure 2: Cubic and prismatic specimens obtained from one brick for compression and Young modulus tests 
Revised version highlighted: Green reviewer \#1, Yellow reviewer \#2
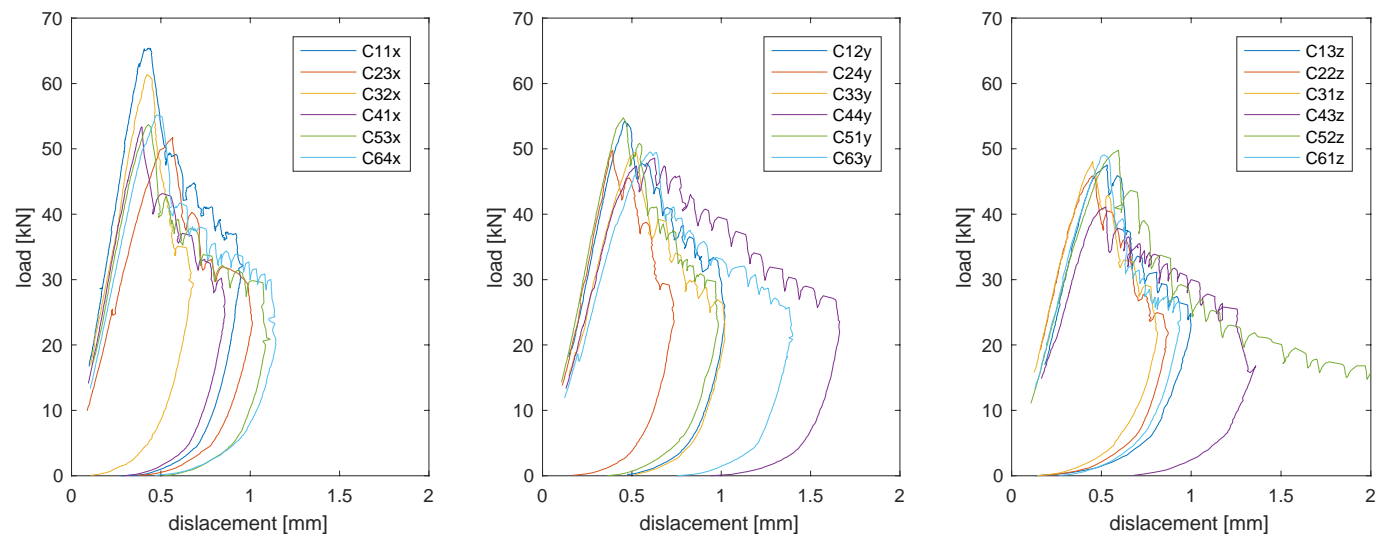

Figure 3: Compression tests on cubic specimens
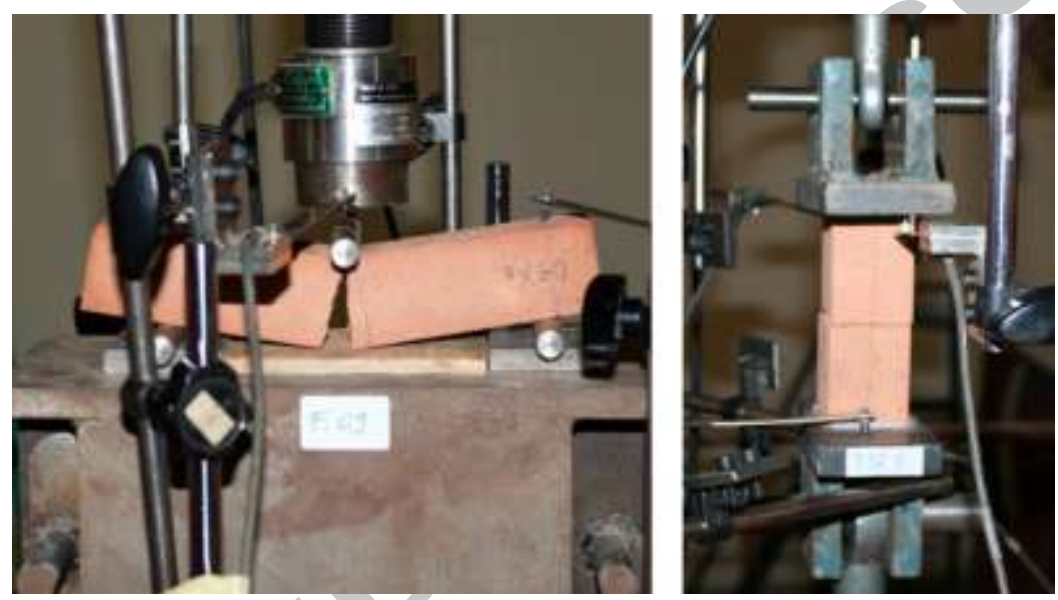

Figure 4: Three point bending and tensile tests on brick specimens.

\begin{tabular}{|c|c|c|c|c|}
\hline & \multirow{2}{*}{ n. specimens } & \multirow{2}{*}{ direction } & Mean & C.V. \\
\hline & & & {$[\mathrm{MPa}]$} & {$[\%]$} \\
\hline \multirow{3}{*}{ Compressive strength } & 6 & $\mathrm{x}$ & 22.17 & 9.28 \\
\hline & 6 & $\mathrm{y}$ & 19.90 & 5.11 \\
\hline & 6 & $\mathrm{Z}$ & 18.22 & 7.40 \\
\hline Young modulus & 6 & $\mathrm{y}$ & 8712 & 6.92 \\
\hline Direct tensile strength & 6 & $\mathrm{y}$ & 2.49 & 16.90 \\
\hline $\begin{array}{l}\text { Bending tensile } \\
\text { strength }\end{array}$ & 6 & $\mathrm{y}$ & 3.36 & 33.77 \\
\hline 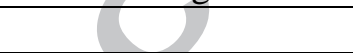 & Table & mechanic & & \\
\hline
\end{tabular}

\subsubsection{Mortar}

For the realization of the masonry specimens, ready mixed mortar made with lime and cement as binder was employed (category M5 according to [40]). Mixed lime and cement mortar was preferred because it exhibits characteristics similar to those of lime mortar, usually employed in historic buildings and traditional architecture, where reinforcement techniques are mainly used for retrofitting and adaptation to standards of structural capacity. On the other side, mixed mortar requires shorter curing time respect to lime mortar, more appropriate to the necessities of a research laboratory.

Six specimens $40 \times 40 \times 160 \mathrm{~mm}$ were poured on custom-made iron mold; after 28 days of curing, the specimens were subjected to three point bending tests. Then, compression tests were performed on the twelve broken halves of the prisms. The tests were carried out according to [29]. The average values of strength are reported in Table 2. 


\begin{tabular}{|c|c|c|c|}
\hline & n. specimens & Mean & C.V. \\
\cline { 2 - 4 } & 6 & {$[\mathrm{MPa}]$} & {$[\%]$} \\
\hline $\begin{array}{c}\text { (Bending) tensile } \\
\text { strength }\end{array}$ & 12 & 1.85 & 9.42 \\
\hline Compressive strength & 5.18 & 8.212 \\
\hline $\begin{array}{r}\text { Table 2: Three point bending tensile strength (specimen's dimensions } 40 \times 40 \times 160 \mathrm{~mm} ; \\
\text { span = } 100 \mathrm{~mm} \text { ) and compressive strength of mortar. }\end{array}$ \\
\hline
\end{tabular}

\subsubsection{Reinforcing composite material (CFRP)}

Unidirectional carbon fiber fabric and epoxy resin were used to realize the reinforcing composite material. These reinforcement sheets were applied to the substrate using a wet lay up process (with a single layer of carbon fiber fabric), after surface preparation and primer application, according to the producer's guideline. In this case, instead of performing laboratory tests, the main characteristics of the constituent materials, declared by the producer were directly considered (Table 3 ).

\begin{tabular}{|c|c|c|c|c|c|c|}
\hline & $\begin{array}{l}\text { Nominal } \\
\text { thickness }\end{array}$ & $\begin{array}{c}\text { Tensile } \\
\text { elastic } \\
\text { modulus }\end{array}$ & $\begin{array}{c}\text { Bending } \\
\text { elastic } \\
\text { modulus }\end{array}$ & $\begin{array}{c}\text { Ultimate } \\
\text { tensile } \\
\text { strain } \\
\end{array}$ & $\begin{array}{l}\text { Characterist } \\
\text { ic tensile } \\
\text { strength }\end{array}$ & $\begin{array}{l}\text { Shear } \\
\text { strength }\end{array}$ \\
\hline & {$[\mathrm{mm}]$} & {$[\mathrm{MPa}]$} & [MPa] & {$[\%]$} & {$[\mathrm{MPa}]$} & [MPa] \\
\hline $\begin{array}{l}\text { Unidirectio } \\
\text { nal carbon } \\
\text { fiber fabric }\end{array}$ & 0.165 & 240000 & & 1.3 & 3200 & -- \\
\hline Adhesive & -- & -- & 2200 & -- & -- & 95 \\
\hline Primer & -- & 1200 & -- & -- & $>20$ & -- \\
\hline
\end{tabular}

Nevertheless, since the adhesion between the units and the reinforcement particularly depends on the characteristics of both materials, pull-off tests have been carried out on reinforced bricks, according to [41], in order to evaluate the bond strength between the CFRP reinforcement and the substrate. To this end, six bricks were reinforced with a CFRP sheet following the indications of the producer, using a wet lay-up procedure as described in section 2.2. The reinforced bricks were prepared with two partially drilled cores; a steel disc, having diameter equal to $75 \mathrm{~mm}$, was then bonded to the circular surface and pulled-off as schematized in Figure 5(c). The bond strength was determined by dividing the maximum pull-off force by the cross-section area of the partial core: the test results are summarized in Table 4. Note that failure always occurred in the substrate (Figure 5(d)), so that the obtained value of tensile strength (1.15 MPa) has to be intended as the pull-off tensile strength of the bricks. Of course, the bond strength between the reinforcement and the substrate is higher than this value. 
Revised version highlighted: Green reviewer \#1, Yellow reviewer \#2

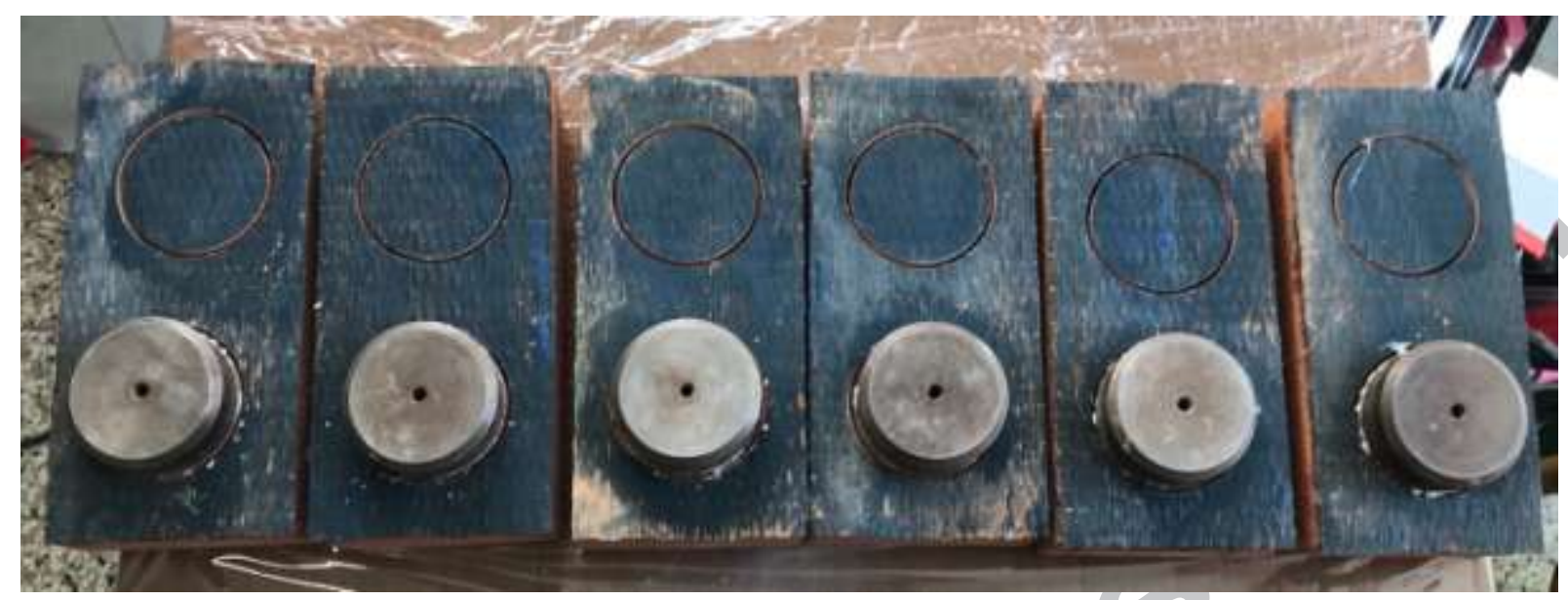

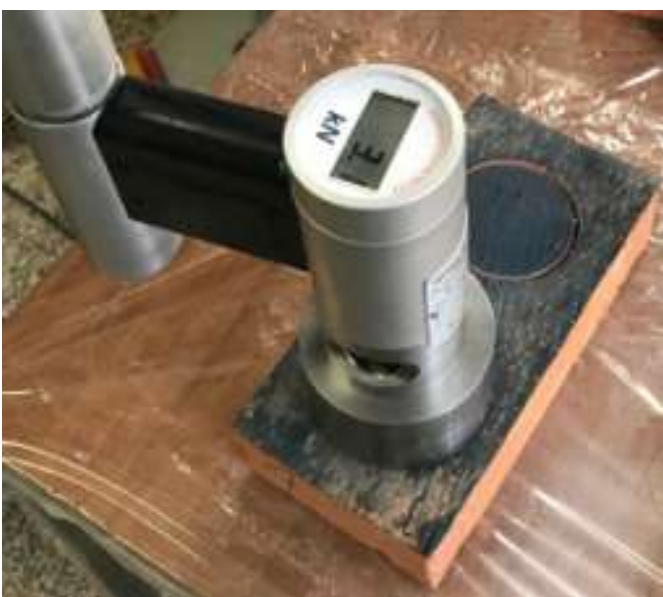

(b)

(a)

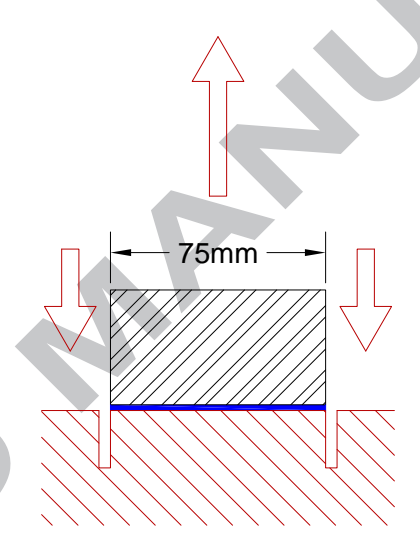

(c)

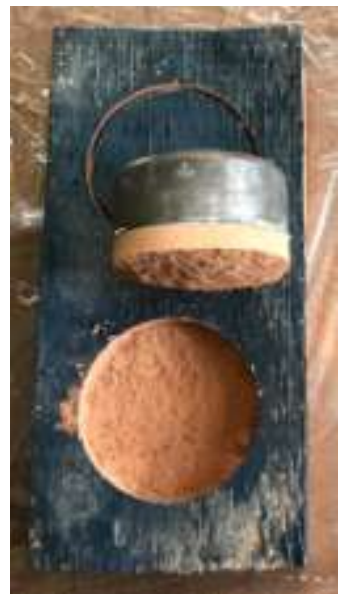

(d)

Figure 5: Pull-off tests on reinforced bricks: (a) specimens preparation; (b) pull-off testing machine; (c) pulloff test scheme; (d) failure mode

\begin{tabular}{|c|c|c|c|}
\hline \begin{tabular}{c} 
Number of tests \\
\cline { 2 - 3 }
\end{tabular} & $\begin{array}{c}\text { Main failure load } \\
{[\mathrm{N}]}\end{array}$ & $\begin{array}{c}\text { Main failure (tensile) } \\
\text { stress } \\
{[\mathrm{MPa}]}\end{array}$ & $\begin{array}{c}\mathrm{C} . \mathrm{V} . \\
{[\%]}\end{array}$ \\
\hline 12 & 5073 & 1.15 & 10.80 \\
\hline
\end{tabular}

\subsection{Specimens}

The characteristics of the accounted specimens together with the label used by the authors for identifying the radius (' $\mathrm{CA}$ ' and ' $\mathrm{CB}$ ' correspond to a radius value of $1500 \mathrm{~mm}$ and $3000 \mathrm{~mm}$ respectively), the strengthening configuration (' $\mathrm{I}-0$ ' and ' $\mathrm{E}-0$ ' correspond to intrados and extrados configuration respectively) and the specimen of the series (' $n$ ' range from 1 to 5 and corresponds to one of specimens composing the series) are reported in Table 5. 


\begin{tabular}{|c|c|c|c|c|}
\hline Series name & n. specimens & $\begin{array}{c}\text { R (internal radius) } \\
{[\mathrm{mm}]}\end{array}$ & $\begin{array}{c}\text { bond length } \\
{[\mathrm{mm}]}\end{array}$ & $\begin{array}{c}\text { Reinforcement } \\
\text { position }\end{array}$ \\
\hline CA-I-0-n & 5 & 1500 & 330 & Intrados \\
\hline CA-E-0-n & 5 & 1500 & 382 & Extrados \\
\hline CB-I-0-n & 5 & 3000 & 330 & Intrados \\
\hline CB-E-0-n & 5 & 3000 & 354 & Extrados \\
\hline \multicolumn{4}{|r}{} \\
\hline
\end{tabular}

Each specimen is representative of portion of double leaf masonry circular arch. In particular, it was manufactured with five soft mud bricks having dimension of $65 \times 120 \times 250 \mathrm{~mm}$ and interposed mortar joints whose thickness varies within the arch depth in order to obtain the requested curvature. In particular the mortar joints thickness at the intrados was $10 \mathrm{~mm}$ for both "CA" and "CB", while at the extrados it was $23 \mathrm{~mm}$ for "CA" and $16 \mathrm{~mm}$ for "CB" (see Figure 6).

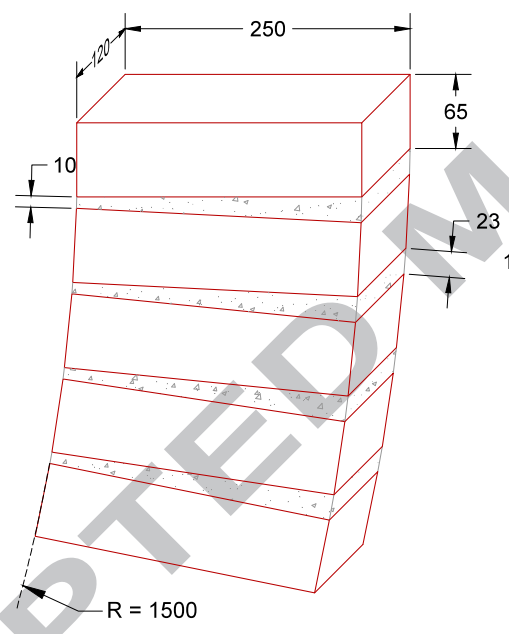

(a)

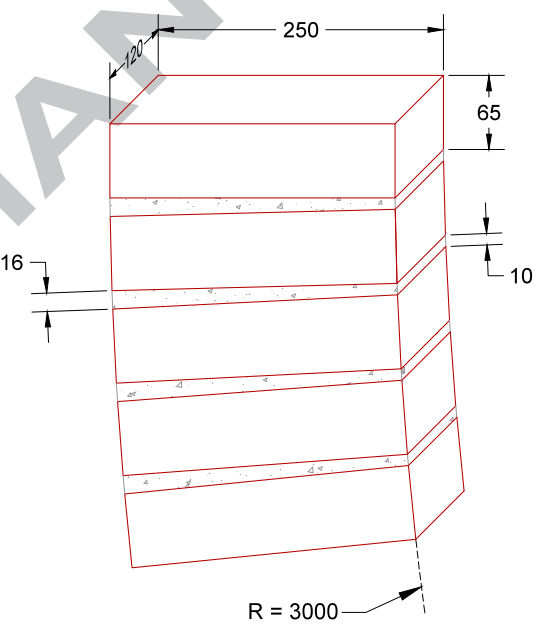

(b)

Figure 6: Specimen's brickwork (measures in mm): (a) CA series; (b) CB series.

Regarding the CFRP reinforcement, the sheets are characterized by the same value of the width (equal to $100 \mathrm{~mm}$ ) for all the specimens, whilst the bond length depends on the configuration of the specimen and the position of the reinforcement (see Table 5). Nevertheless, considering the formulas reported in [11] for the evaluation of the effective bond length of FRPs applied on masonry flat surfaces, the bond length values accounted in the experimental program are significant greater than the theoretical effective bond length $\left(l_{\text {eff }}=122 \mathrm{~mm}\right)$. Of course, this estimation could not be reliable for curved surfaces, but can be considered at least to have a first dimensioning of the reinforcements considered in this paper, seeing the lack in the literature of specific design formulas.

Moreover, in order to avoid stress concentrations on the bricks located at the ends of the masonry specimens, the bond length of strips does not cover the external edges of these bricks (see Figure 7). 

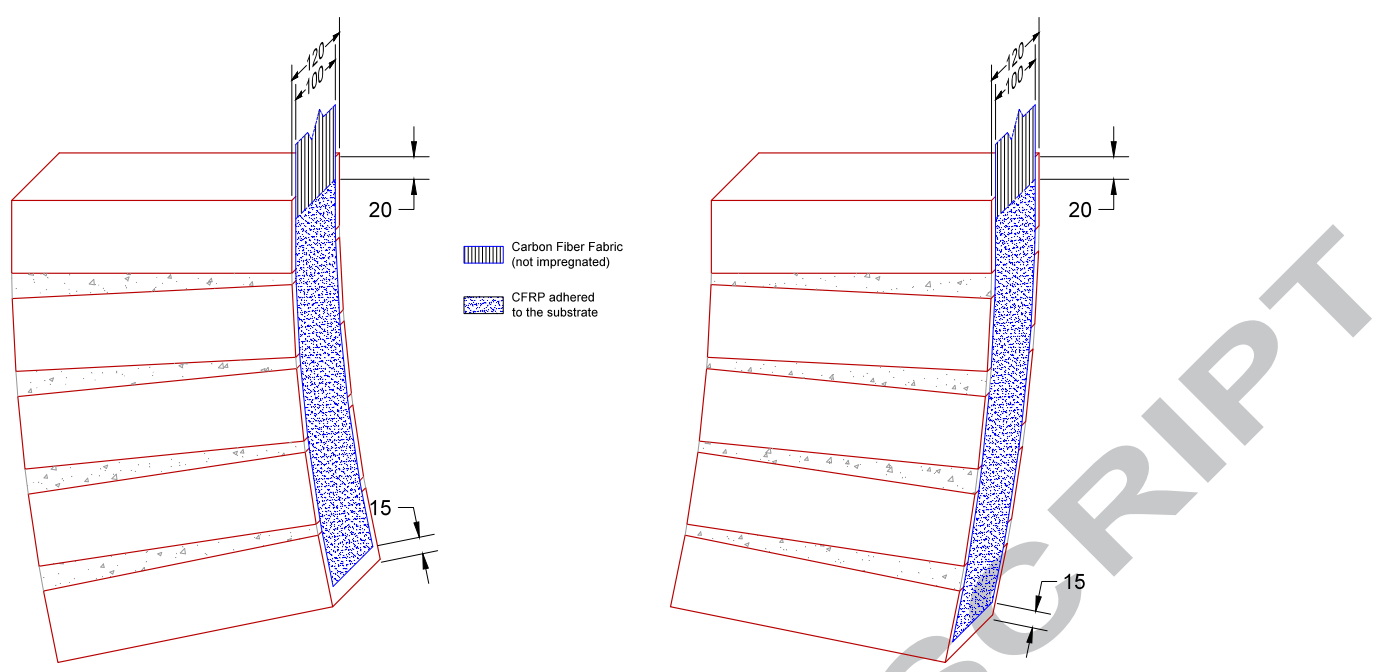

Figure 7: geometric characteristics of the CFRP reinforcements considered in the experimental program (measures in mm): (a) extrados; (b) intrados

Regarding the manufacturing process of masonry specimens (Figure 8), during the curing phase, the specimens were confined and left in a horizontal position in order to avoid plastic deformation and/or shearing between the bricks at the joints. Moreover, the masonry specimens were cured for at least 28 days at room environment; then, the CFRP reinforcements were applied using a wet lay-up procedure, following the indications of the producer (Figure 9): the substrate surface was sanded and cleaned; the primer was spread over the masonry surface to be reinforced; then, within twenty-four hours, a layer of epoxy resin was spread and a single layer of carbon fiber fabric was laid on it. At this point, a second layer of epoxy resin was spread as to form a composite having total thickness equal to $1 \mathrm{~mm}$. Due to the different lengths of the bonded surfaces in specimens having different curyature and reinforced at the extrados and intrados, the total length of the carbon fiber fabric was $763 \mathrm{~mm}$ for "CA-I-0" and "CB-I-0" series, $787 \mathrm{~mm}$ for "CB-E-0" series and $815 \mathrm{~mm}$ for "CA-E-0" series. As previously said, a portion of such fiber fabric, having length ranging from 330 to $382 \mathrm{~mm}$, was impregnated with the epoxy resin and bonded to the masonry specimen. On the other hand, a length equal to $433 \mathrm{~mm}$ was not impregnated and used to apply the load. The specimens were tested after the hardening time of the CFRP reinforcement (minimum 24 hours, as indicated by the producer). 


\section{ACCEPTED MANUSCRIPT}

\section{Revised version highlighted: Green reviewer \#1, Yellow reviewer \#2}
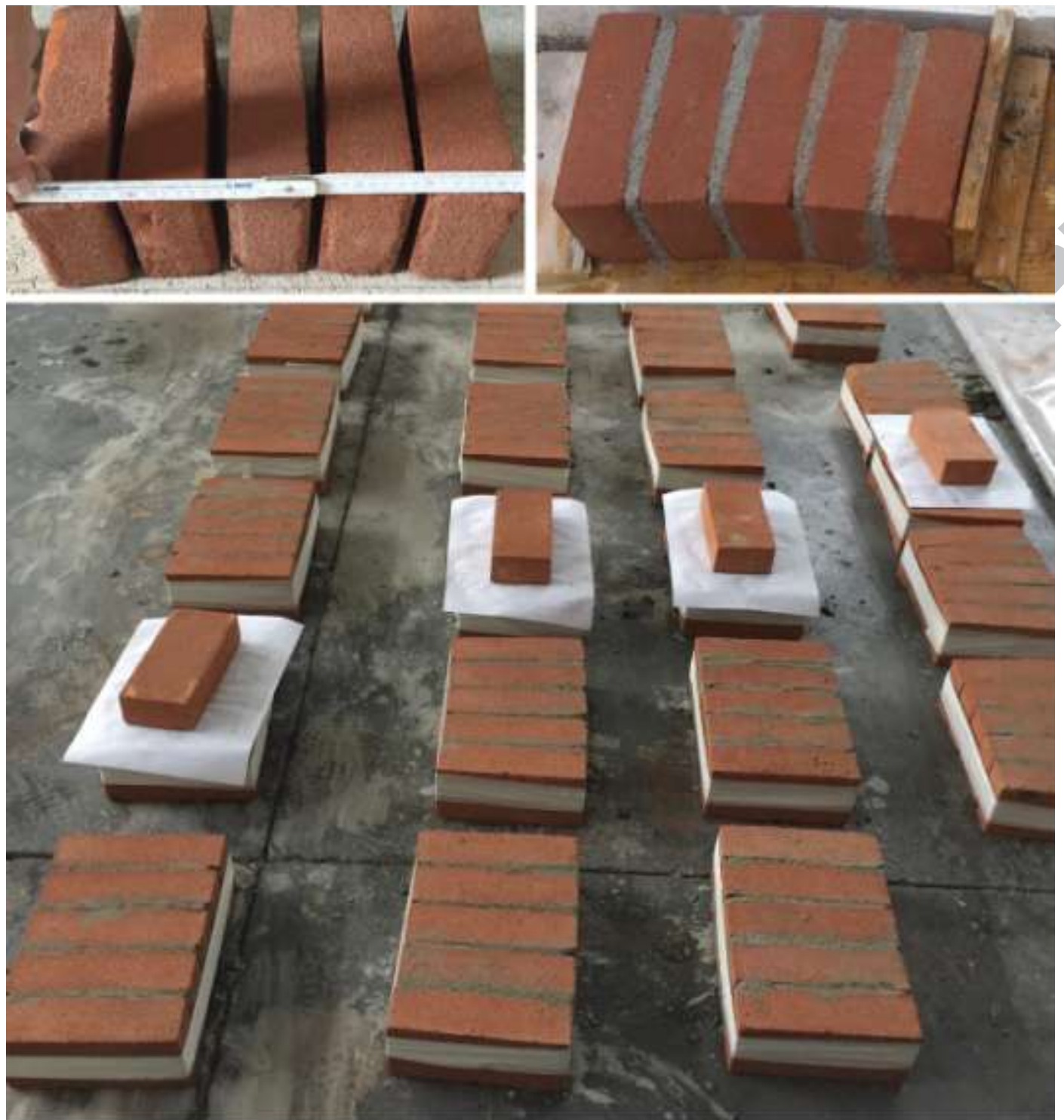

Figure 8: Manufacturing of masonry specimens
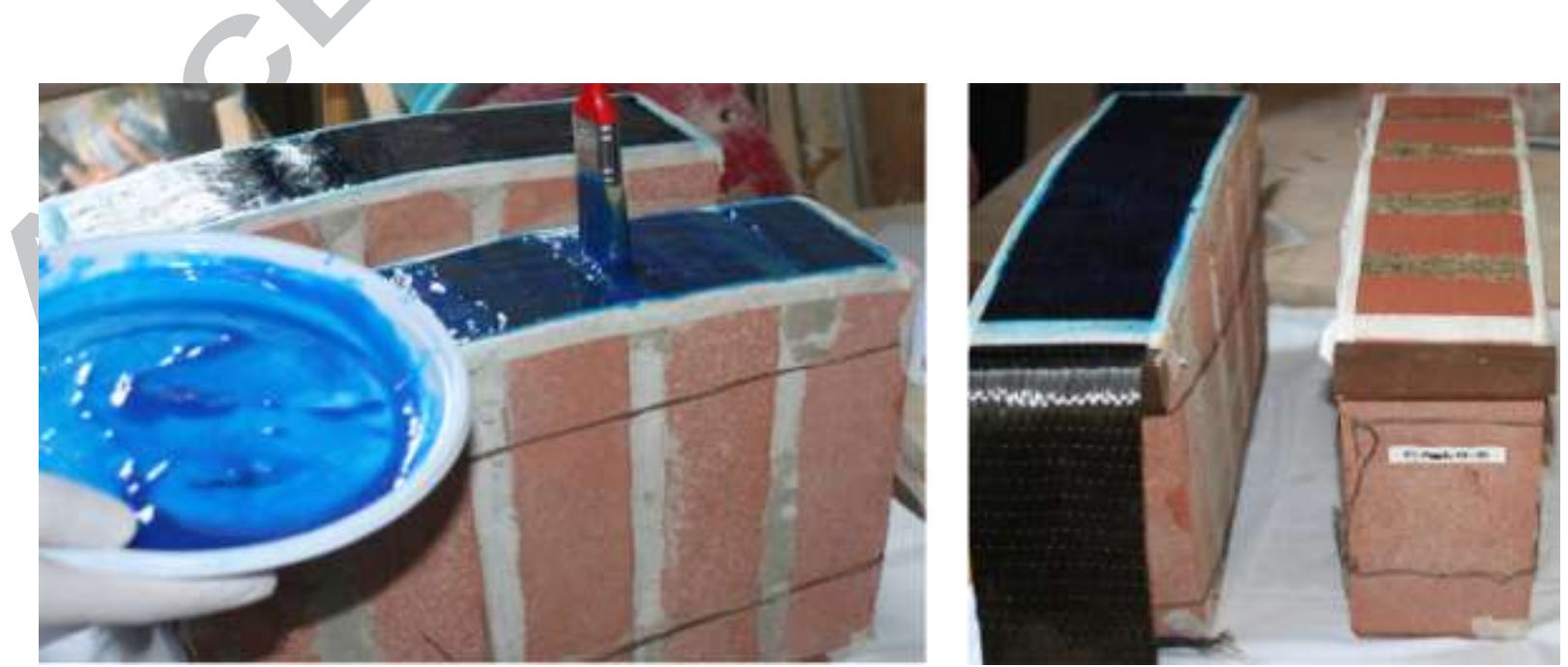

Figure 9: Reinforcement application 


\subsection{Test setup}

The so called Single Lap Shear Tests $[10,16]$ scheme was considered in the experimental campaign, so that a force tangent to an end of the reinforcement bonded to the specimens was applied (Figure 1). This is a standard test scheme used in others experimental programs, so that the results of the present experimental campaign can be directly compared with literature results, and in particular with experimental programs involving analogous reinforcements (and substrates) applied to plane surfaces. In so doing, it is possible to evaluate the influence of surface curvature on the structural response of the considered reinforcement systems.

The test apparatus and measuring instruments are schematized in Figure 10. The specimens were constrained by a steel plate at the upper base and by a steel wedge at the lower base. Given the different inclination of the lower face of the specimens due to the different curvature of "CA" and "CB" specimens, two different wedges have been used. The upper plate and the lower wedge were linked by four steel bars, properly pretensioned in order to give a little pre-compression to the specimens, necessary to ensure the stability of the specimens during the tests. Note that the steel wedge is provided of a little steel plate (Figure 10) to constrain the specimen, preventing its rotation.

The specimens were loaded imposing the vertical displacement of the upper grip consisting of a fork and a steel cylinder having a diameter equal to $60 \mathrm{~mm}$. In order to apply the load, the final portion of the (dry) reinforcement fabric was wrapped and glued to the steel cylinder, for a length of $283 \mathrm{~mm}$ (equal to 1.5 times the length of the circumference of the steel cylinder base); after gluing, the length of the dry reinforcement fabric was equal to $150 \mathrm{~mm}$ (Figure 10). The fabric was glued to the steel cylinder after the realization of the reinforcement sheet and before the specimen was placed into the test machine. At this stage it was possible to easily check that the threads of the fabric were well aligned orthogonally to the axis of the steel cylinder and to the upper face of the masonry specimens, as to properly apply an action tangent to the reinforcement surface. Moreover, it was checked that the threads length was constant, in order to ensure that the load was evenly distributed across all the fabric. The gripping system selected in the experimental program, compared with other methods such as using jaws, has the advantage that, by virtue of the curvature of the glued surface, the load applied to the specimen increases the adhesion between the glued portion of the reinforcing fabric and the steel cylinder.

The steel fork was connected in series to a load cell $(50 \mathrm{kN})$ and then to a screw jack. In so doing, the tensile load was applied directly to the reinforcement sheet and was transferred to the specimen. Two displacement transducers ("TL" and "TR" in Figure 10) were placed at the bottom of the load cell and based on the contrast plate of the steel frame, so that they could record the relative displacement between the fork and the upper face of the brick. Moreover, two displacement transducers ("T1" and "T2" in Figure 10) measured the vertical displacement of the steel plate as a check of possible translations and rotations of the upper constraining plate of the steel frame. Moreover, two "omega" transducers ("O1" and "O2" in Figure 10) measured directly the slip between the upper end of the CFRP reinforcement and the masonry substrate.

Three specimens of each series were also equipped with four strain gauges, glued to the external surface of the CFRP reinforcement as described in Figure 10.

The load was applied increasing monotonically the displacement, at a constant rate of $0.015 \mathrm{~mm} / \mathrm{s}$, up to the specimens failure. 
Revised version highlighted: Green reviewer \#1, Yellow reviewer \#2

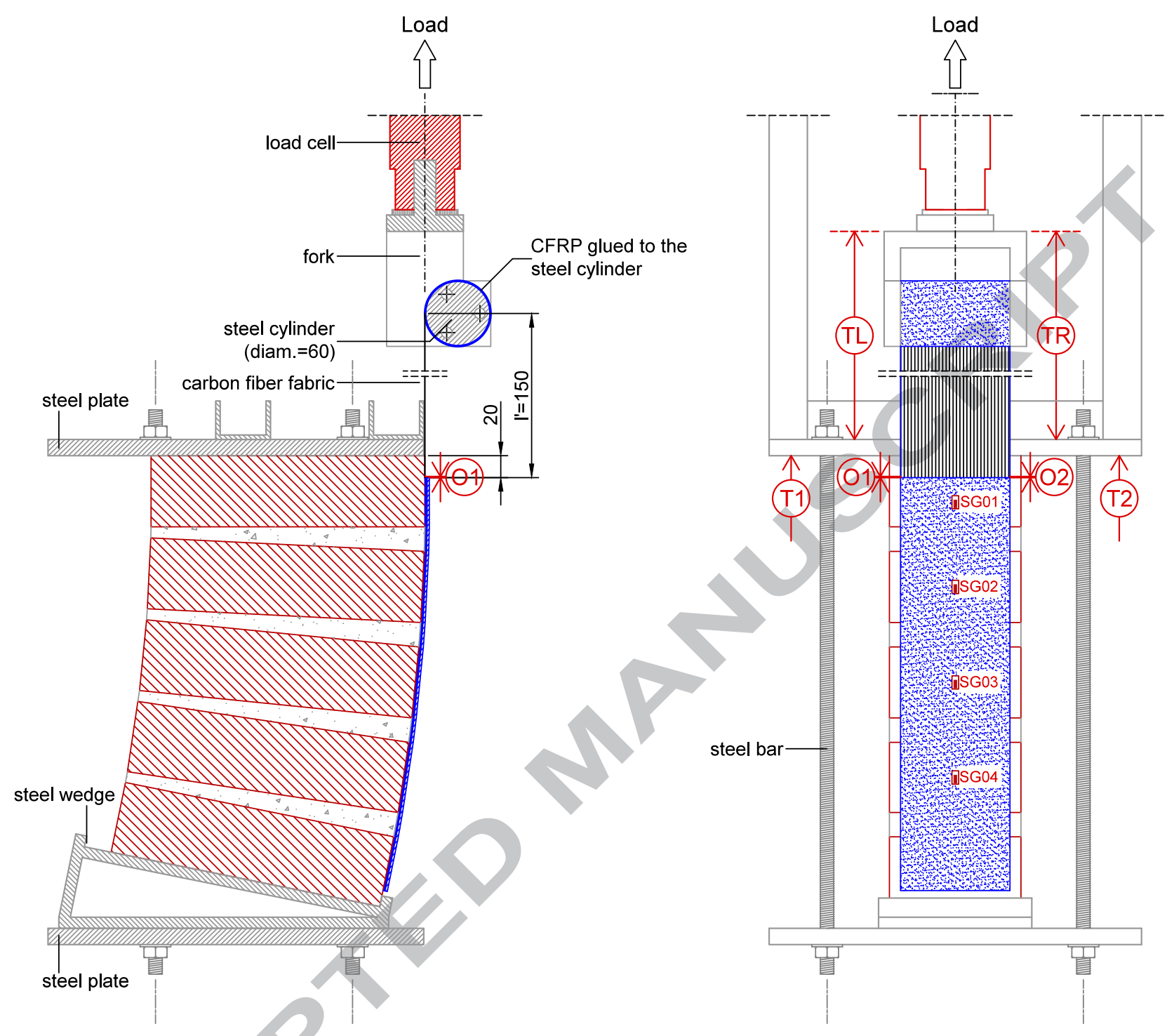

Figure 10: Test setup and instrumentation

\section{Experimental results}

The outcomes emerged from the performed single lap shear tests are here reported in terms of forcedisplacement curves, failure modes and strain profiles. They allow to understand the bond behaviour of specimens by emphasizing the role of the curvature of the masonry substrate and the strengthening configuration.

\subsection{Load-displacement curves}

In Figure 11 are reported the load-displacements curves experimentally derived from the single shear lap tests. In particular, the displacement corresponds to the relative displacement between the rigid plate, constraining the upper specimen surface, and the load grip (measured by the transducers "TL" and "TR" indicated in Figure 10), minus the elastic deformation of the dry fiber fabric sheet out of the reinforcement bonding (width=100 $\mathrm{mm}$; length=150 mm), estimated by using the elastic modulus and the nominal thickness declared by the producer (see Table 3 ). 
Revised version highlighted: Green reviewer \#1, Yellow reviewer \#2

From the plots emerges a similar behaviour of specimens in the pre-peak stage. Indeed, considering the representative load-displacement plot shown in Figure 12 it is possible to identify the following common three phases:

- phase 1: a quasi-linear branch (whose slope has been indicated as $\mathrm{K}_{0}$ ) characterizes the load-displacement curves up to the formation of the first crack occurring in the masonry substrate close to the loaded end of the CFRP reinforcement (point $\mathrm{P}_{\mathrm{f}}$ );

- phase 2: although the diagram still shows a quasi-linear branch up to the first peak $\mathrm{K}_{0}$, a reduction of the slope of the load-displacement curves occurs: this phenomenon is mainly due to the formation of microcracks developing behind the CFRP-to-substrate bonded joint, in the area close to the loaded end of the reinforcement, where the first crack occurred at $\mathrm{P}_{\mathrm{f}}$;

- phase 3: load drops characterize the branch of the load-displacement curve (the most evident one occurs after the attainment of $\mathrm{P}_{1}$ ). In this phase the load continues growing until the attainment of the peak load $\left(\mathrm{F}_{\max }\right)$, corresponding to the point $\mathrm{P}_{\mathrm{Fmax}}$ in Figure 12. Cracks advance by inyolving a wider region of the masonry substrate, moving from the loaded end of the CFRP reinforcement to the bottom.

Note that the first crack point $P_{f}$ is not always easily identifiable in all the diagrams reported in Figure 11, since these are almost linear up to $P_{1}$. Therefore, in order to identify $P_{f}$, the load-displacement diagrams were analyzed together with the values measured by the strain gauges: at $\mathrm{P}_{\mathrm{f}}$, in fact, the strain values measured by SG01 (Figure 10) sharply increased. Furthermore, the time and load value at which first cracks occurred in the specimens were recorded during the tests.

After the attainment of $\mathrm{P}_{\mathrm{Fmax}}$ the load-displacement curves exhibit a very scattered equilibrium path up the ultimate displacement (corresponding to the point $\mathrm{P}_{\mathrm{U}}$ ). Moreover, as underlined by the plots of Figure 11, the shape of the load-displacement curves after $\mathrm{P}_{1}$ particularly depends on the reinforcement configuration (i.e. intrados or extrados arrangement) and also on the curvature radius. Indeed, while in the case of specimens strengthened at the extrados the load almost increases up to the failure (this aspect is more evident for specimens with lower curvature radius CA-E-0), in the case of specimens strengthened at the intrados, the load tends to reduce (this effect is particular evident for specimens characterized by a lower value of the radius, CA-I-0).

Both the evidences underline the influence of normal stresses developing at the reinforcement-masonry interface on the adhesion of FRP. Indeed, both the value and type (tension of compression) of normal stresses depend on the geometry radius of the masonry substrate and the strengthening configuration. 

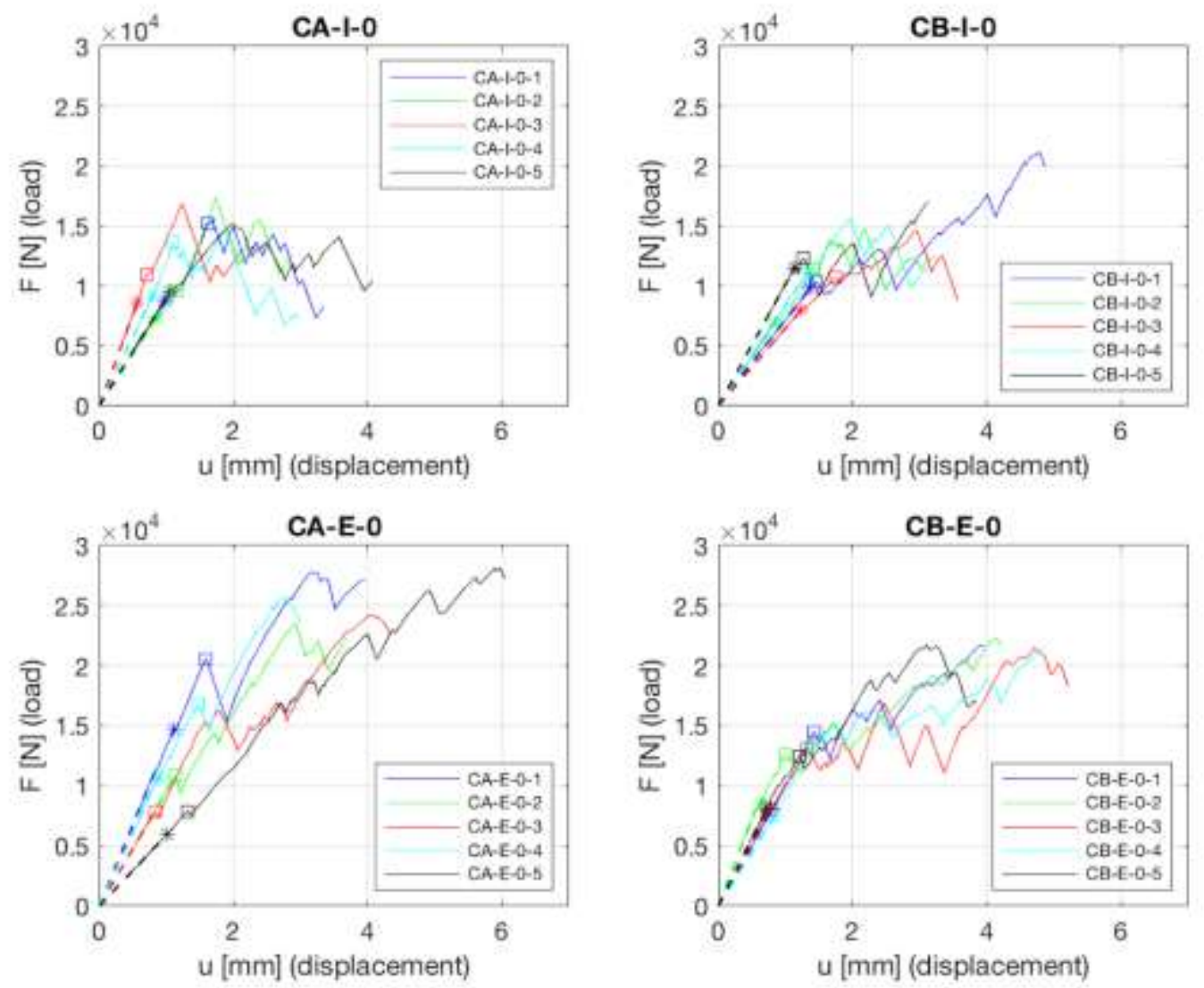

Figure 11: Experimental load-displacement diagrams; * and $\square$ correspond respectively to first cracks ( $\left.\mathrm{P}_{\mathrm{f}}\right)$ and first peak $\left(\mathrm{P}_{1}\right)$ points.

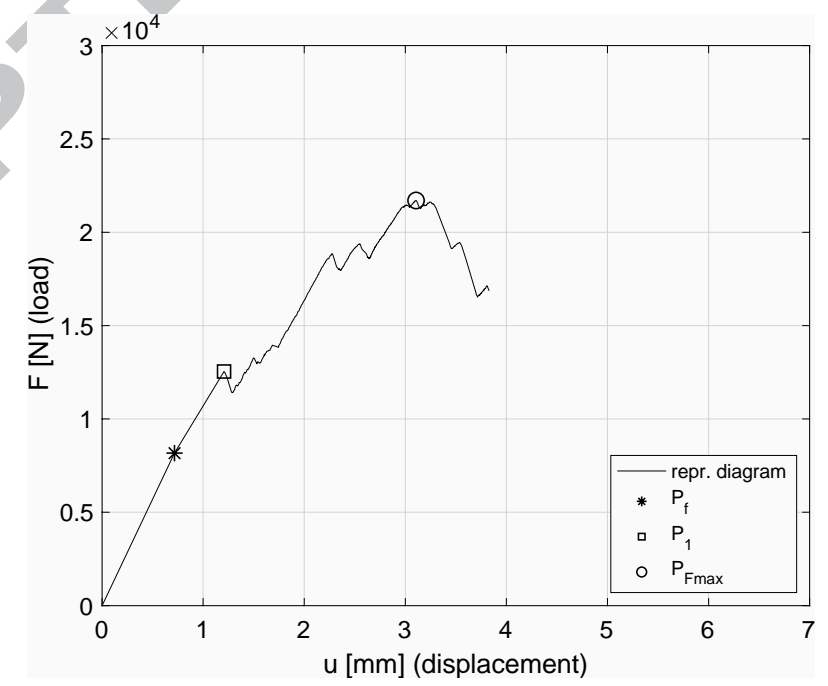

Figure 12: Representative load-displacement diagram; $\mathrm{P}_{\mathrm{f}}$ : first cracks point; $\mathrm{P}_{1}$ : first peak point; $\mathrm{P}_{\mathrm{Fmax}}$ : maximum load point. 


\begin{tabular}{|c|c|c|c|c|c|c|c|}
\hline \multirow[b]{2}{*}{ Specimen } & \multirow[b]{2}{*}{ Failure mode } & \multicolumn{2}{|c|}{$\mathrm{F}_{\max }$} & \multicolumn{2}{|c|}{$\mathrm{K}_{0}$} & \multicolumn{2}{|c|}{$\mathrm{K}_{0 \Omega}$} \\
\hline & & {$[\mathrm{N}]$} & $\begin{array}{l}\text { mean } \\
\text { (C.V.) }\end{array}$ & {$[\mathrm{N} / \mathrm{mm}]$} & $\begin{array}{l}\text { mean } \\
\text { (C.V.) }\end{array}$ & {$[\mathrm{N} / \mathrm{mm}]$} & $\begin{array}{l}\text { mean } \\
\text { (C.V.) }\end{array}$ \\
\hline CA-I-0-1 & CF-IF & 15545 & \multirow{5}{*}{$\begin{array}{c}15928 \\
(7.18 \%)\end{array}$} & 8846 & \multirow{5}{*}{$\begin{array}{c}10633 \\
(25.97 \%)\end{array}$} & 202640 & \multirow{5}{*}{$\begin{array}{c}147086 \\
(36.43 \%)\end{array}$} \\
\hline CA-I-0-2 & CF-IF & 17367 & & 8658 & & 78045 & \\
\hline CA-I-0-3 & CF-IF & 16864 & & 15125 & & 128114 & \\
\hline CA-I-0-4 & CF-IF & 14657 & & 11483 & & 126283 & \\
\hline CA-I-0-5 & CF-IF & 15208 & & 9054 & & 200347 & \\
\hline CB-I-0-1 & CF-IF -PF & 21198 & \multirow{5}{*}{$\begin{array}{c}16646 \\
(16.33 \%)\end{array}$} & 7179 & \multirow{5}{*}{$\begin{array}{c}8074 \\
(17.23 \%)\end{array}$} & $--\infty$ & \multirow{5}{*}{$\begin{array}{l}-- \\
(--)\end{array}$} \\
\hline CB-I-0-2 & CF-IF & 14773 & & 8154 & & $4-2$ & \\
\hline CB-I-0-3 & CF-IF & 14632 & & 6486 & & 396923 & \\
\hline CB-I-0-4 & $\mathrm{CF}$ & 15582 & & 8403 & & -- & \\
\hline CB-I-0-5 & CF-IF & 17043 & & 10149 & & -- & \\
\hline CB-E-0-1 & CF-PF & 21718 & \multirow{5}{*}{$\begin{array}{c}21737 \\
(1.61 \%)\end{array}$} & 10061 & & 247943 & \multirow{5}{*}{$\begin{array}{c}222085 \\
(10.79 \%)\end{array}$} \\
\hline CB-E-0-2 & CF-PF & 22323 & & 14533 & & 193588 & \\
\hline CB-E-0-3 & CF-PF & 21499 & & 10590 & 110 & -- & \\
\hline CB-E-0-4 & CF-PF & 21440 & & 8994 & 48 & 212488 & \\
\hline CB-E-0-5 & $\mathrm{CF}$ & 21703 & & 11317 & & 234320 & \\
\hline CA-E-0-1 & $\mathrm{CF}$ & 27805 & \multirow{5}{*}{$\begin{array}{c}25895 \\
(7.97 \%)\end{array}$} & 13479 & \multirow{5}{*}{$\begin{array}{c}10135 \\
(28.78 \%)\end{array}$} & 128082 & \multirow{5}{*}{$\begin{array}{c}179123 \\
(38.05 \%)\end{array}$} \\
\hline CA-E-0-2 & $\mathrm{CF}$ & 23583 & & 9565 & & -- & \\
\hline CA-E-0-3 & $\mathrm{CF}$ & 24169 & & 9519 & & -- & \\
\hline CA-E-0-4 & $\mathrm{FF}$ & 25773 & & 12204 & & 152767 & \\
\hline CA-E-0-5 & $\mathrm{CF}$ & 28145 & & 5907 & & 256519 & \\
\hline \multicolumn{8}{|c|}{ Table 6: Experimental results } \\
\hline
\end{tabular}

The maximum load $\left(\mathrm{F}_{\max }\right)$ and initial stiffness $\left(\mathrm{K}_{0}\right)$ values are reported in Table 6 for all the examined specimens. It can be noted that the initial stiffness of the specimens $\left(\mathrm{K}_{0}\right)$ is almost independent on the curvature and on the bonded surface of the reinforcement (intrados or extrados). This result was expected since, in the initial phase of the tests, stress is almost concentrated in the upper part of the specimens, behind the loaded end of the reinforcement, that is in the first voussoir that has the reinforced face tangent to the load direction for all the series. For the same reason, the first crack and the first peak loads (resp. $F_{P f}$ anf $F_{P 1}$ ) are almost constant for all the series (see Table 7 and Figure 13). Moreover, the maximum load $\left(\mathrm{F}_{\max }\right)$ is almost independent on the curvature when the reinforcement was applied at the intrados (CA-I-0 and CB-I-0 series). This occurs because, for reinforcements bonded at the intrados, behind $\mathrm{P}_{1}$ the reinforcement partially detaches from the substrate and in-plane actions combine to peeling effects, generating the gradual detachment of the reinforcement at an almost constant load level. Contrariwise, the capacity of the reinforcement increases with the curvature, because of confining effects, if it is bonded at the extrados. Moreover, the ultimate load $\left(\mathrm{F}_{\mathrm{U}}\right)$ exhibited a trend with respect to the curvature analogous to $\mathrm{F}_{\max }$. Note that, the values of maximum load within each series have low statistical dispersion, since the coefficient of variation ranges from 1.61 to $16.33 \%$.

The mean values of the displacements recorded at the characteristic points of the load-displacement diagrams are reported in Table 7. It is apparent that the trend of such displacements is almost analogous to the one of the corresponding load values. In fact, the displacement values corresponding to $\mathrm{P}_{\mathrm{f}}$ and $\mathrm{P}_{1}$ are almost independent on the curvature and on the position of the bonding surface, while $\mathrm{u}_{U}$ increase with the curvature. Note that $\mathrm{u}_{\mathrm{Fmax}}$, only for the reinforcements applied at the extrados, decreases with the curvature. Of course, such trend should be validated by further tests.

The post peak behaviour of the considered reinforcements can be analysed through the displacement ratios reported in Table 8 . The ratio $\mathrm{u}_{\mathrm{Fmax}} / \mathrm{u}_{\mathrm{P} 1}$ has higher values for reinforcements bonded at the extrados, while ratio $\mathrm{u}_{\mathrm{U}} / \mathrm{u}_{\mathrm{Fmax}}$ is higher for reinforcements bonded at the intrados, so that the load displacement diagrams 
Revised version highlighted: Green reviewer \#1, Yellow reviewer \#2

referring to CA-I-0 and CB-I-0 exhibited a longer post- $\mathrm{F}_{\max }$ branch. Anyhow, the reinforcements bonded at the extrados showed a longer post $\mathrm{P}_{1}$ branch (see $\mathrm{u}_{\mathrm{U}} / \mathrm{u}_{\mathrm{P} 1}$ in Table 8).

\begin{tabular}{|c|c|c|c|c|c|c|c|c|}
\hline Series & $\begin{array}{c}\mathrm{F}_{\mathrm{Pf}} \\
{[\mathrm{N}]} \\
\text { (C.V.) }\end{array}$ & $\begin{array}{c}\mathrm{F}_{\mathrm{P} 1} \\
{[\mathrm{~N}]} \\
\text { (C.V.) }\end{array}$ & $\begin{array}{c}\mathrm{F}_{\max } \\
{[\mathrm{N}]} \\
\text { (C.V.) } \\
\end{array}$ & $\begin{array}{c}\mathrm{F}_{\mathrm{U}} \\
{[\mathrm{N}]} \\
\text { (C.V.) }\end{array}$ & $\begin{array}{c}\mathrm{u}_{\mathrm{Pf}} \\
{[\mathrm{mm}]} \\
(\mathrm{C} . \mathrm{V} .)\end{array}$ & $\begin{array}{c}\mathrm{u}_{\mathrm{P} 1} \\
{[\mathrm{~mm}]} \\
\text { (C.V.) }\end{array}$ & $\begin{array}{c}\mathrm{u}_{\mathrm{Fmax}} \\
{[\mathrm{mm}]} \\
\text { (C.V.) }\end{array}$ & $\begin{array}{c}\mathrm{u}_{\mathrm{U}} \\
{[\mathrm{mm}]} \\
\text { (C.V.) }\end{array}$ \\
\hline CA-I-0 & $\begin{array}{c}8679 \\
(9.76 \%)\end{array}$ & $\begin{array}{c}12339 \\
(20.91 \%)\end{array}$ & $\begin{array}{c}15928 \\
(7.18 \%)\end{array}$ & $\begin{array}{c}10303 \\
(24.02 \%)\end{array}$ & $\begin{array}{c}0.85 \\
(22.25 \%)\end{array}$ & $\begin{array}{c}1.15 \\
(32.95 \%)\end{array}$ & $\begin{array}{c}1.70 \\
(16.96 \%)\end{array}$ & $\begin{array}{c}3.07 \\
(23.31 \%)\end{array}$ \\
\hline CB-I-0 & $\begin{array}{c}9475 \\
(21.30 \%) \\
\end{array}$ & $\begin{array}{c}11187 \\
(8.03 \%) \\
\end{array}$ & $\begin{array}{c}16646 \\
(16.33 \%)\end{array}$ & $\begin{array}{c}13848 \\
(32.63 \%)\end{array}$ & $\begin{array}{c}1.18 \\
(17.80 \%)\end{array}$ & $\begin{array}{c}1.48 \\
(13.35 \%) \\
\end{array}$ & $\begin{array}{c}3.00 \\
(37.16 \%) \\
\end{array}$ & $\begin{array}{c}3.57 \\
(20.0 \%) \\
\end{array}$ \\
\hline CB-E-0 & $\begin{array}{c}8100 \\
(4.65 \%)\end{array}$ & $\begin{array}{c}13217 \\
(5.96 \%) \\
\end{array}$ & $\begin{array}{c}21737 \\
(1.61 \%)\end{array}$ & $\begin{array}{c}19998 \\
(11.40 \%)\end{array}$ & $\begin{array}{c}0.75 \\
(10.42 \%)\end{array}$ & $\begin{array}{c}1.27 \\
(13.92 \%)\end{array}$ & $\begin{array}{c}4.15 \\
(16.85 \%)\end{array}$ & $\begin{array}{c}4.41 \\
(13.54 \%)\end{array}$ \\
\hline CA-E-0 & $\begin{array}{c}10453 \\
(41.51 \%)\end{array}$ & $\begin{array}{c}12803 \\
(44.07 \%)\end{array}$ & $\begin{array}{c}25895 \\
(7.97 \%)\end{array}$ & $\begin{array}{c}20258 \\
(51.54 \%)\end{array}$ & $\begin{array}{c}1.00 \\
(11.67 \%)\end{array}$ & $\begin{array}{c}1.27 \\
(23.75 \%)\end{array}$ & $\begin{array}{c}3.75 \\
(34.50 \%)\end{array}$ & $\begin{array}{c}4.60 \\
(20.46 \%)\end{array}$ \\
\hline
\end{tabular}
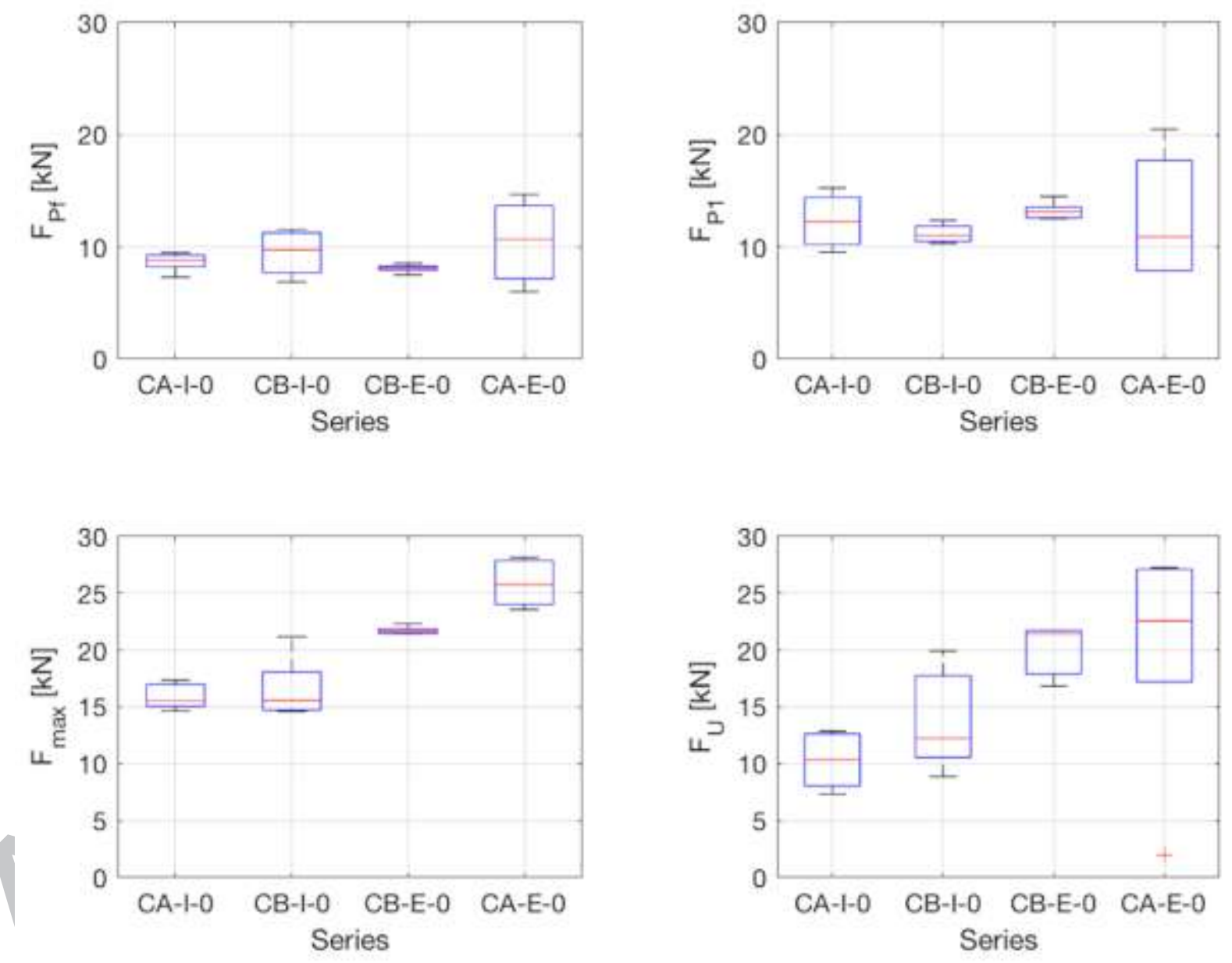

Figure 13: Box-plot of the representative load values. On each box, the central mark indicates the median, the bottom and top edges of the box indicate the 25th and 75th percentiles, respectively. The whiskers extend to the most extreme data points not considered outliers, and the outliers are plotted individually using the ' + ' symbol [42]. 


\begin{tabular}{|c|ccc|}
\hline Series & $\begin{array}{c}\mathrm{u}_{\mathrm{Fmax}} / \mathrm{u}_{\mathrm{P} 1} \\
{[]} \\
\text { (C.V.) }\end{array}$ & $\begin{array}{c}\mathrm{u}_{\mathrm{U}} / \mathrm{u}_{\mathrm{Fmax}} \\
{[]} \\
\text { (C.V.) }\end{array}$ & $\begin{array}{c}\mathrm{u}_{\mathrm{U}} / \mathrm{u}_{\mathrm{P} 1} \\
{[]} \\
\text { (C.V.) }\end{array}$ \\
\hline \hline CA-I-0 & 1.50 & 1.79 & 2.56 \\
& $(21.98 \%)$ & $(11.54 \%)$ & $(15.65 \%)$ \\
\hline CB-I-0 & 2.23 & 1.26 & 2.51 \\
& $(35.64 \%)$ & $(21.03 \%)$ & $(22.22 \%)$ \\
\hline CB-E-0 & 3.30 & 1.07 & 3.51 \\
& $(19.81 \%)$ & $(9.26 \%)$ & $(16.69 \%)$ \\
\hline CA-E-0 & 3.15 & 1.28 & 3.79 \\
& $(45.10 \%)$ & $(23.97 \%)$ & $(29.50 \%)$ \\
\hline
\end{tabular}

Table 8: displacement ratios: mean values and coefficient of variation

As described in section 2.3, the specimens were equipped with two "omega" transducers ("O1" and "O2" in Figure 10) measuring directly the slip between the upper end of the CFRP reinforcement and the masonry substrate. To this end aluminium elements were glued at the reinforcement and at the substrate as showed in Figure 14. In some tests the gluing did not work properly, so that the "omega" displacements were not considered reliable and were not reported in this paper. For all the other tests, the gluing system worked properly until the first cracks occurred in the specimens. After that, the aluminium elements detached from the reinforcement or exhibited finite rotations, such that the measured displacement values could not be considered reliable. The load-slip diagrams, referring to only the "reliable" part of the measured slips, are showed in Figure 15. Even if, as described, these diagrams are incomplete, they provide important information, such as the initial stiffness $\left(\mathrm{K}_{0 \Omega}\right)$ reported in Table 6 that should be considered to calibrate an interface model schematizing the mechanical behaviour of the reinforcements here considered. It is noteworthy that $\mathrm{K}_{0 \Omega}$ is of one order of magnitude higher than the corresponding $\mathrm{K}_{0}$ values. This occurs because $\mathrm{K}_{0}$ refers to the global behaviour of the specimens and is affected by spurious effects related to the test setup and to the specimens positioning. For this reason, in order to assess load-slip diagrams referring to the entire equilibrium path, the load-displacement diagrams in Figure 11 have been "shifted-back" (see Figure 16) using the following procedure:

- from O to $\mathrm{P}_{1}$. The slip value $\bar{s}$ has been estimated from the displacement value (u) in Figure 11 using the following equation

$$
\bar{s}(F)=u(F)-\left(\frac{1}{K_{0}}-\frac{1}{K_{0 \Omega}}\right) F
$$

where $F$ is the load value, $K_{0}$ refers to the specific specimen, $K_{0 \Omega}$ refers to the specific specimen or, if such value is not available (see Table 6 ), to the average value of the series:

- from $\mathrm{P}_{1}$ to $\mathrm{P}_{\mathrm{U}}$. The load-displacement diagrams in Figure 11 were simply shifted-back, just to join the first part of the diagram, as follows

$$
\bar{s}(F)=u(F)-\left(\frac{1}{K_{0}}-\frac{1}{K_{0 \Omega}}\right) F_{P 1}
$$

Of course, in so doing we have just an estimation of the load-slip curves. 
Revised version highlighted: Green reviewer \#1, Yellow reviewer \#2

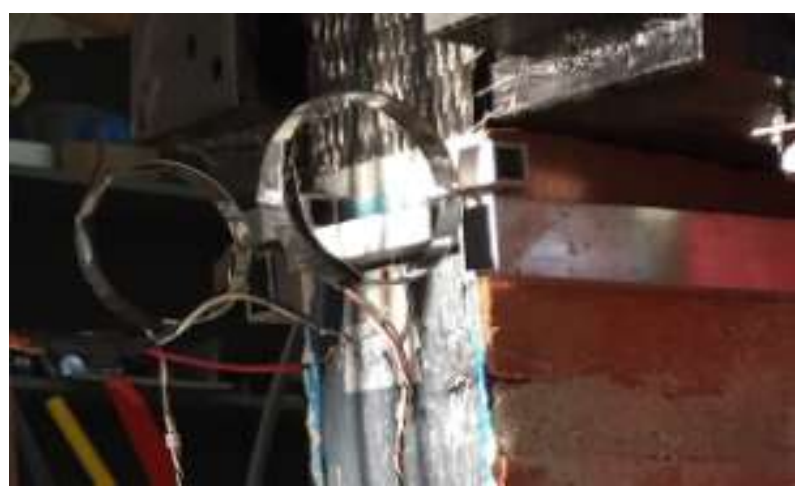

Figure 14: Omega transducers
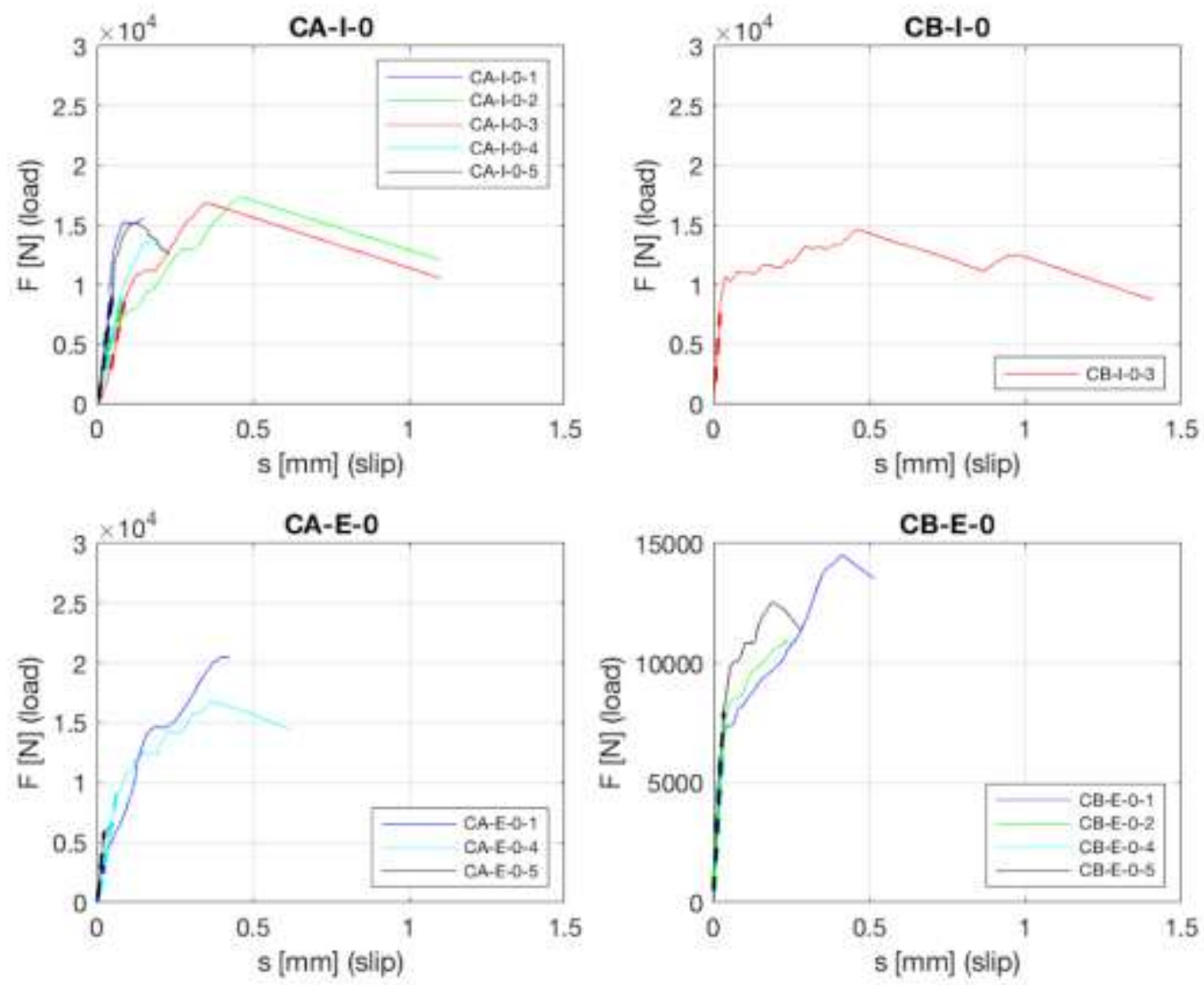

Figure 15: Experimental load - (omega) displacement diagrams 

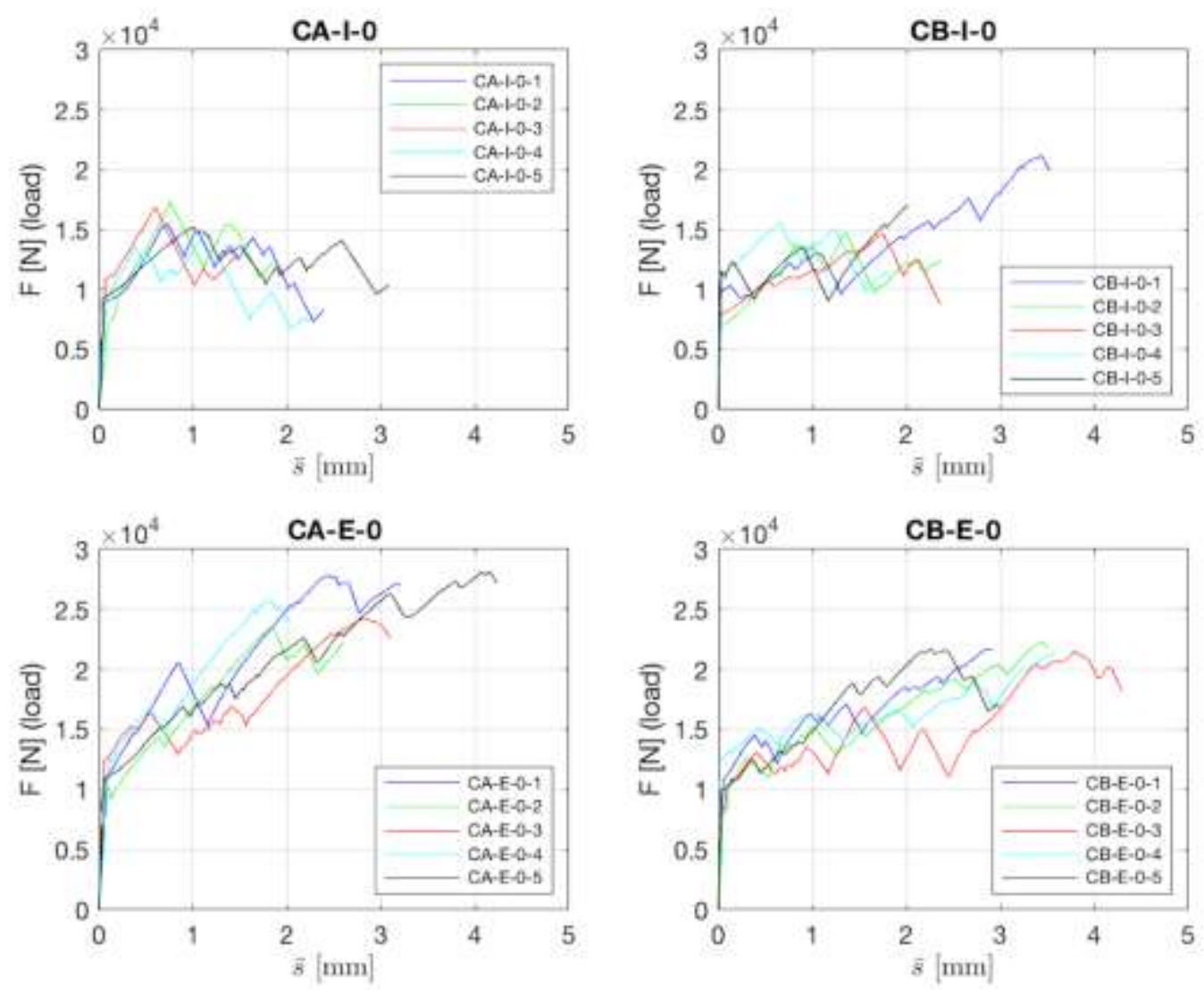

Figure 16: Load - "shifted omega displacement" diagrams

\subsection{Failure modes}

In Figure 17 are reported pictures of the main failure modes observed during the performed single lap shear tests. In particular, the authors have identified the following four failure modes (Table 6):

a) Cohesive Failure ("CF" mode): it involves the substrate material where cracks involving few millimetres of the CFRP-masonry interface occur;

b) Interface Failure ("IF" mode): it refers to the detachment to the CFRP reinforcement from the substrate;

c) Prismatic Failure ("PF" mode): it occurs with the detachment of a prismatic shaped portion of brick;

d) Fiber Failure ("FF" mode): it concerns the tensile failure of the dry carbon fiber fabric, outside the CFRP composite.

From Table 6 clearly emerges that the majority of the specimens reinforced at the intrados exhibited a combination of "CF" and "IF" modes: "CF" mode occurred at the "upper" part of the reinforcement (close to the loaded end), while "IF" mode occurred at the end part of the reinforcement, far from the loaded end. This is related to the fact that in the initial part of the test, only debonding effects are generated by the load, while in the final part of the tests, when the CFRP reinforcement is partially detached from the substrate, also peeling effects are produced. The failure mode of only one specimen of CB-I-0 series was associate to "PF" mode.

Conversely, almost all the specimens reinforced at the extrados exhibited a "CF" mode; this was generally associated to "PF" mode for specimens of CB-E-0 (having lower curvature, so that the bonding surface being closer to a plane) as occurred for plane masonry specimens tested in the experimental campaign described in [19-21,43]. Only one specimen of CA-E-0 series exhibited "FF" mode: in this case, the maximum load 
Revised version highlighted: Green reviewer \#1, Yellow reviewer \#2

reached during the tests is almost equal to $50 \%$ of the nominal tensile capacity of the carbon fabric, determined according to the values reported in Table 3. This can be due to a uneven distribution of the tensile load in the fabric, related to a not perfect positioning of the specimen during the test. However, the maximum load of this specimen is not very different from the average value of the series.

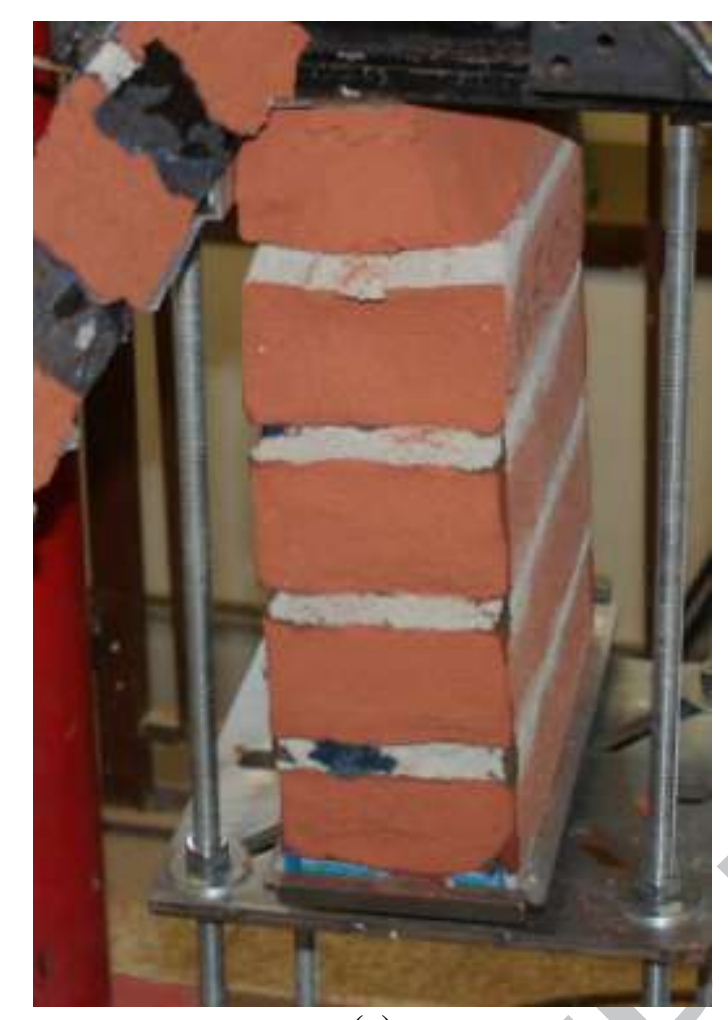

(a)

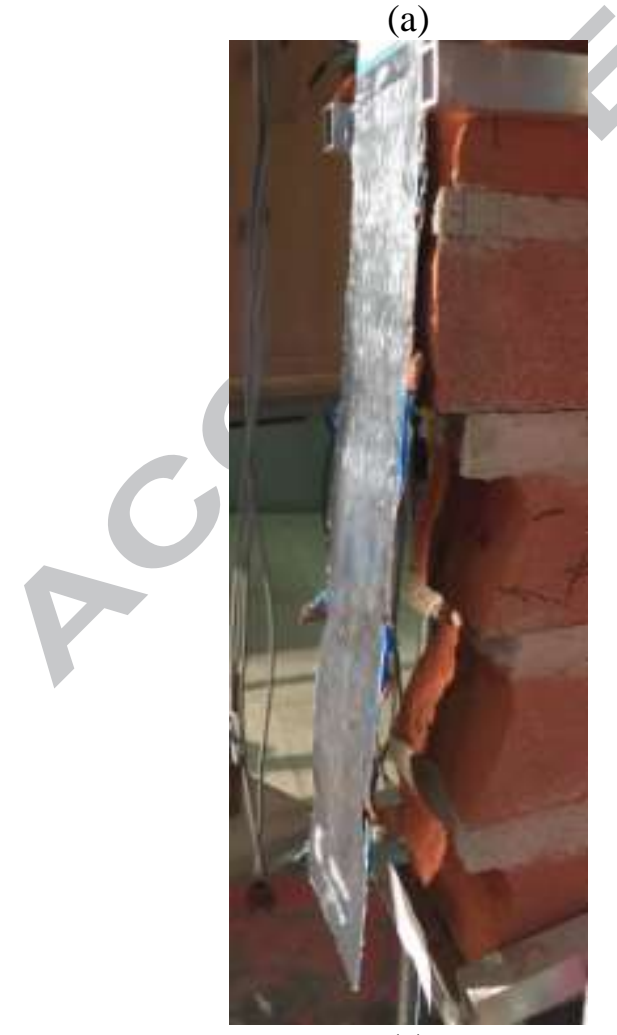

(c)

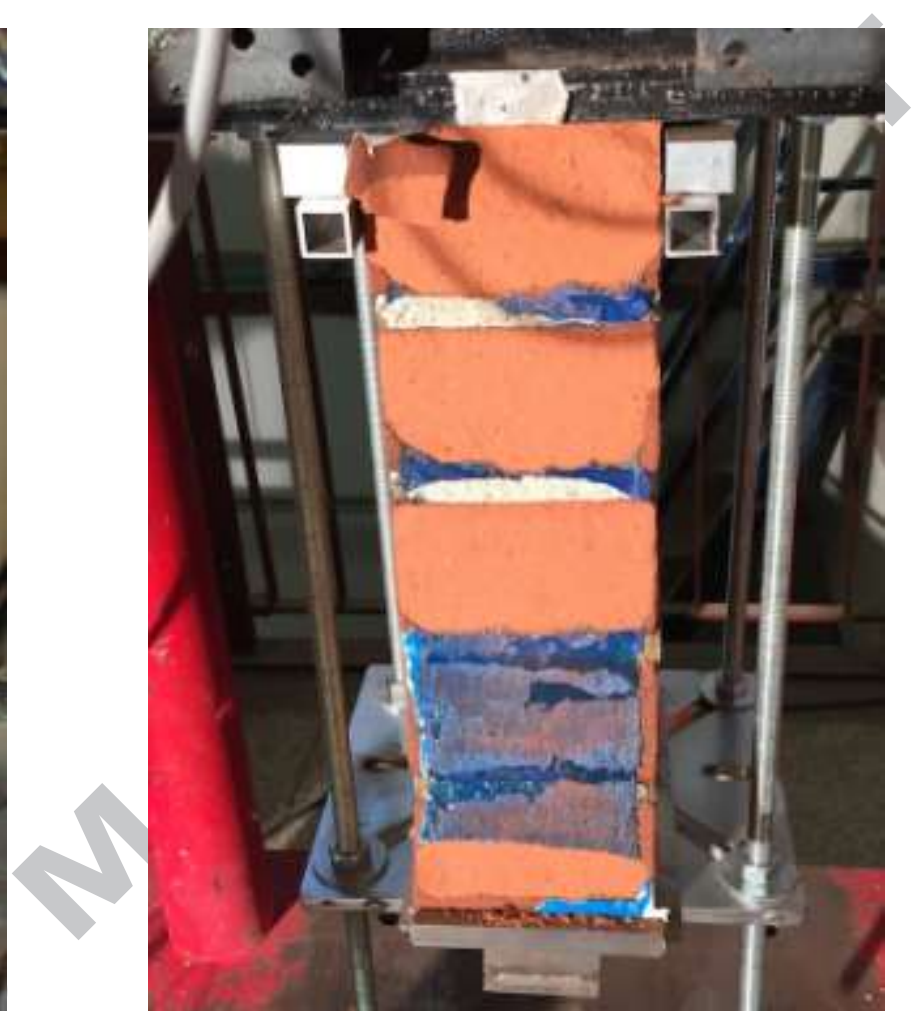

(b)

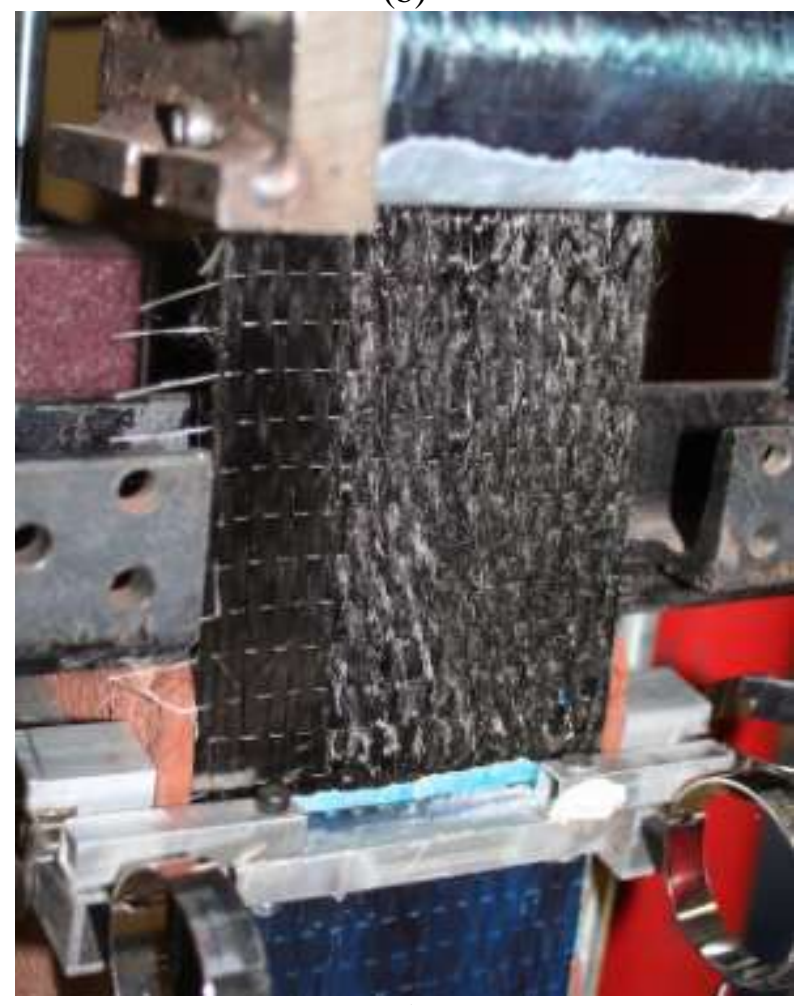

(d)

Figure 17: Failure modes: (a) "Cohesive Failure" (CF); (b) combination of "Cohesive Failure" (CF) and "Interface Failure" (IF) modes; (c) "Prismatic Failure" (PF); (d) "Fiber Failure" (FF) 


\subsection{Strain profiles}

Finally, the strain profiles obtained using the values recorded by SG01 to SG04 (see Figure 10) at the characteristic load levels $\left(\mathrm{F}_{\mathrm{Pf}}, \mathrm{F}_{\mathrm{P} 1}, \mathrm{~F}_{\max }\right.$ and $\left.\mathrm{F}_{\mathrm{U}}\right)$ are reported in Figure 18. In abscissa the distance between the strain gauge and the upper face of the specimen is represented.

The strain profiles show that the length of the reinforcement sheet mainly involved in carrying the applied load increases with the load itself. Up to $\mathrm{F}_{\mathrm{P} 1}$, in fact, only the first strain gauge (SG01) recorded significant measures. Then, increasing the load, also the others strain gauges measured significant values. It is noteworthy that reinforcements bonded at the intrados or at the extrados showed quite different behaviour: in CA-I-0 and CB-I-0 series only the first brick was involved in carrying the applied up to $\mathrm{F}_{\text {max }}$, being the strain value recorded by SG02 considerably lower than the one recorded by SG01. Conversely, for reinforcements bonded at the extrados, at least the first three bricks are involved in bearing the applied load at $\mathrm{F}_{\max }$. The crack patterns occurred during the tests confirm this different behaviour: at $\mathrm{F}_{\max }$, it was almost concentrated at the first brick, while it was distributed also on the second and third bricks for reinforcements bonded at the extrados. Note that, at the maximum load, SG04 recorded almost negligible strain values: this indicates that the bonding length of the reinforcement is higher than the effective one. Finally, the strain profiles at $F_{U}$ are not very regular: this is due to the failure mechanism involving cracks in the substrate, which nucleates and propagates underneath the bond surface in the substrate. This produces local bending of the reinforcement sheet and consequent rotation of its outer surface.
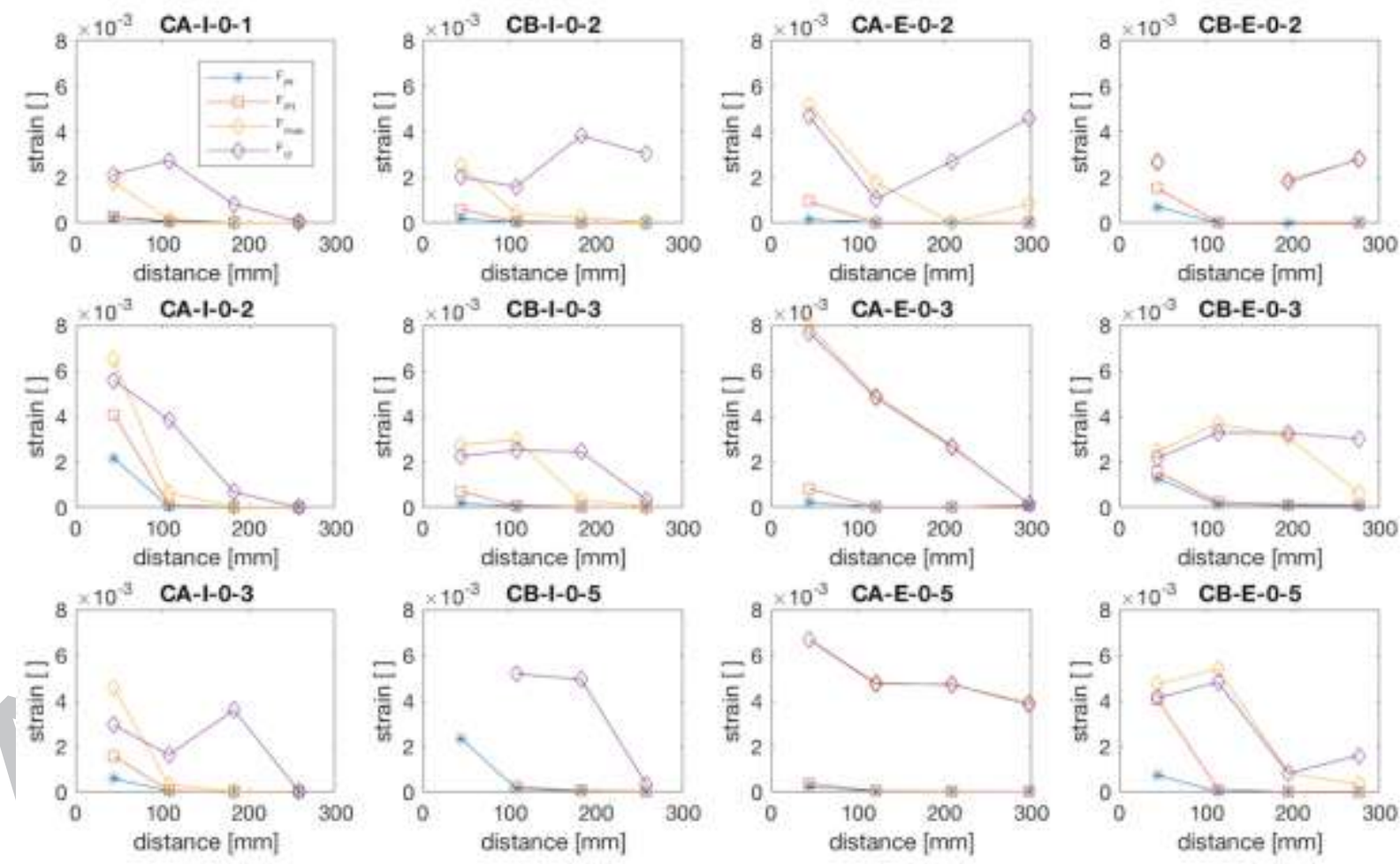

Figure 18: Strain Profiles

\section{Conclusions}

The results of an experimental campaign, devoted to the analysis of the effect of the curvature of the bonding surface on the mechanical behaviour of CFRP sheet reinforcements applied to masonry specimens, have been described in this paper. Masonry specimens, representative of portion of masonry arches (two different curvatures), have been reinforced at the intrados or extrados and were tested using a single lap shear test 
scheme. The mechanical properties of the materials employed in the experimental campaign have been identified through ad hoc tests. The experimental results have showed that:

- the first crack and the first peak loads are almost independent on the position of the reinforcement and on the curvature;

- the load bearing capacity of reinforcements bonded at the extrados is higher than reinforcements applied at the intrados; as expected, the capacity of reinforcements bonded at the extrados (intrados) increases (decreases) with the curvature;

- the initial stiffness $\left(\mathrm{K}_{0}\right.$ or $\left.\mathrm{K}_{0 \Omega}\right)$ is almost independent on the curvature and on the position of the reinforcement;

- the reinforcements bonded at the extrados showed a longer post $\mathrm{P}_{1}$ branch, estimated by the ratio $\mathrm{u}_{\mathrm{U}} / \mathrm{u}_{\mathrm{P} 1}$;

- when the maximum load was reached, for reinforcements bonded at the intrados, only the first brick was involved in carrying the applied load; conversely, for reinforcements bonded at the extrados, at least the first three bricks are involved in bearing the applied load at $\mathrm{F}_{\max }$,

- all the data recorded during the tests allowed to estimate the load-slip curves, required to schematize the mechanical behaviour of the reinforcements through an interface model.

Of course, given the limited number of specimen tested, the experimental results should be integrated and validated by further tests. Note that, the experimental campaign described in the paper was designed to analyze the bond behavior of the considered reinforcements applied to curved surfaces. Further tests should be necessary to investigate its effectiveness for different loading and boundary conditions.

\section{Acknowledgements}

The Authors gratefully acknowledge the financial support provided by the Italian Department of Civil Protection and ReLUIS (Rete dei Laboratori Universitari di Ingegneria Sismica), 2014- 2016 Grant - Innovative Materials.

Moreover, BASF and TERREAL-SANMARCO are gratefully acknowledged for providing material.

\section{References}

[1] Foraboschi P. Effectiveness of novel methods to increase the FRP-masonry bond capacity. Compos Part B Eng 2016;107:214-32. doi:10.1016/j.compositesb.2016.09.060.

[2] Hosseini A, Mostofinejad D, Emami M. Influence of bonding technique on bond behavior of CFRPto-clay brick masonry joints: Experimental study using particle image velocimetry (PIV). Int J Adhes Adhes 2015;59:27-39. doi:10.1016/j.ijadhadh.2015.01.015.

[3] Carrara P, Ferretti D, Freddi F. Debonding behavior of ancient masonry elements strengthened with CFRP sheets. Compos Part B-Engineering 2013;45:800-10. doi:Doi 10.1016/J.Compositesb.2012.04.029.

[4] Carloni C, Focacci F. FRP-masonry interfacial debonding: An energy balance approach to determine the influence of the mortar joints. Eur J Mech - A/Solids 2016;55:122-33. doi:http://dx.doi.org/10.1016/j.euromechsol.2015.08.003.

[5] Fagone M, Ranocchiai G. On the mechanical behaviour of anchored CFRP-to-masonry reinforcements. In: Modena C, da Porto F, Valluzzi MR, editors. 16th Int. Brick Block Mason. Conf., Padova, Italy: Taylor \& Francis Group; 2016, p. 387-93. 
Revised version highlighted: Green reviewer \#1, Yellow reviewer \#2

[6] Fagone M, Ranocchiai G. An Experimental Analysis of the Mechanical Behaviour of Anchored CFRP-to-Masonry Reinforcements Loaded by Out-of-Plane Actions. In: Di Tommaso A, Gentilini C, Castellazzi G, editors. Mech. Mason. Struct. Strengthened with Compos. Mater. II - MuRiCo5, Bologna, Italia: Trans Tech Publications; 2017, p. 204-11.

doi:10.4028/www.scientific.net/KEM.747.204.

[7] Sorrentino L, D'Ayala D, de Felice G, Griffith MC, Lagomarsino S, Magenes G. Review Of Out-OfPlane Seismic Assessment Techniques Applied To Existing Masonry Buildings. Int J Archit Herit 2016;0:15583058.2016.1237586. doi:10.1080/15583058.2016.1237586.

[8] Bruggi M, Milani G. Optimal FRP reinforcement of masonry walls out-of-plane loaded: A combined homogenization-topology optimization approach complying with masonry strength domain. Comput Struct 2015;153:49-74. doi:http://dx.doi.org/10.1016/j.compstruc.2015.02.004.

[9] Hamed E, Rabinovitch O. Failure characteristics of FRP-strengthened masonry walls under out-ofplane loads. Eng Struct 2010;32:2134-45. doi:http://dx.doi.org/10.1016/j.engstruct.2010.03.016.

[10] Rotunno T, Rovero L, Tonietti U, Briccoli Bati S. Experimental Study of Bond Behavior of CFRP-toBrick Joints. J Compos Constr 2015;19:4014063. doi:10.1061/(asce)cc.1943-5614.0000528.

[11] National Research Council. CNR-DT 200/R1: Istruzioni per la Progettazione, l'Esecuzione ed il Controllo di Interventi di Consolidamento Statico mediante l'utilizzo di Compositi Fibrorinforzati 2013.

[12] Grande E, Imbimbo M, Sacco E. Bond behaviour of CFRP laminates glued on clay bricks: Experimental and numerical study. Compos Part B-Engineering 2011;42:330-40. doi:10.1016/j.compositesb.2010.09.020.

[13] Fedele R, Milani G. A numerical insight into the response of masonry reinforced by FRP strips. The case of perfect adhesion. Compos Struct 2010;92:2345-57. doi:Doi 10.1016/J.Compstruct.2010.03.014.

[14] Fedele R, Milani G. Assessment of bonding stresses between FRP sheets and masonry pillars during delamination tests. Compos Part B Eng 2012;43:1999-2011.

doi:http://dx.doi.org/10.1016/j.compositesb.2012.01.080.

[15] Grande E, Imbimbo M, Sacco E. Bond Behavior of Historical Clay Bricks Strengthened with Steel Reinforced Polymers (SRP). Materials (Basel) 2011;4:585-600. doi:10.3390/ma4030585.

[16] Valluzzi MR, Oliveira D V, Caratelli A, Castori G, Corradi M, de Felice G, et al. Round Robin Test for composite-to-brick shear bond characterization. Mater Struct 2012;45:1761-91.

doi:10.1617/s11527-012-9883-5.

[17] Grande E, Imbimbo M, Sacco E. The role of the adhesive on the bond behavior of SRPs applied on masonry supports: Experimental and numerical study. vol. 624. 2015.

doi:10.4028/www.scientific.net/KEM.624.652.

[18] Grande E, Imbimbo M, Sacco E. Investigation on the bond behavior of clay bricks reinforced with SRP and SRG strengthening systems. Mater Struct Constr 2015;48:3755-70. doi:10.1617/s11527014-0437-x.

[19] Caggegi C, Pensee V, Fagone M, Cuomo M, Chevalier L. Experimental global analysis of the efficiency of carbon fiber anchors applied over CFRP strengthened bricks. Constr Build Mater 2014;53:203-12. doi:10.1016/j.conbuildmat.2013.11.086.

[20] Fagone M, Ranocchiai G, Caggegi C, Briccoli Bati S, Cuomo M. The efficiency of mechanical anchors in CFRP strengthening of masonry: An experimental analysis. Compos Part B Eng 2014;64:1-15. doi:10.1016/j.compositesb.2014.03.018. 
Revised version highlighted: Green reviewer \#1, Yellow reviewer \#2

[21] Fagone M, Ranocchiai G, Briccoli Bati S. An experimental analysis about the effects of mortar joints on the efficiency of anchored CFRP-to-masonry reinforcements. Compos Part B-Engineering 2015;76:133-48. doi:10.1016/j.compositesb.2015.01.050.

[22] Ceroni F. Bond tests to evaluate the effectiveness of anchoring devices for CFRP sheets epoxy bonded over masonry elements. Compos Part B Eng 2017;113:317-30. doi:10.1016/j.compositesb.2017.01.042.

[23] Witzany J, Brožovský J, Čejka T, Kroftová K, Kubát J, Makovička D, et al. The Application of Carbon Composites in the Rehabilitation of Historic Baroque Vaults. Polymers (Basel) 2015;7:2670_ 89. doi:10.3390/polym7121540.

[24] Carozzi FG, Poggi C, Bertolesi E, Milani G. Ancient masonry arches and vaults strengthened with TRM, SRG and FRP composites: Experimental evaluation. Compos Struct 2018;187:466-80. doi:10.1016/j.compstruct.2017.12.075.

[25] Oliveira D V, Basilio I, Lourenco PB. Experimental Behavior of FRP Strengthened Masonry Arches. J Compos Constr 2010;14:312-22. doi:10.1061/(asce)cc.1943-5614.0000086.

[26] Briccoli Bati S, Rotunno T, Soraci A. Indagine sperimentale sul comportamento strutturale di archi in muratura rinforzati con SRP e SRG. Work. Des. Rehabil. Mason. Struct., Inchia, Italy: Edizioni Polistampa; 2007, p. 441-51.

[27] Pintucchi B, Zani N. A simple model for performing nonlinear static and dynamic analyses of unreinforced and FRP-strengthened masonry arches. Eur J Mech A/Solids 2016;59:210-31. doi:10.1016/j.euromechsol.2016.03.013.

[28] Foraboschi P. Strengthening of masonry arches with fiber-reinforced polymer strips. J Compos Constr 2004;8:191-202. doi:10.1061/(Asce)1090-0268(2004)8:3(191).

[29] Borri A, Castori G. Damage and Seismic Vulnerability of the Portal of Palazzo Dei Priori. Int J Archit Herit 2011;5:219-40. doi:10.1080/15583050903511606.

[30] Briccoli Bati S, Fagone M. Lunghezza ottimale di ancoraggio per rinforzi in FRP su elementi in laterizio. Valutazione e riduzione della vulnerabilità sismica di Edif. esistenti c.a., Roma: 2008, p. 18.

[31] D'Ambrisi A, Feo L, Focacci F. Masonry arches strengthened with composite unbonded tendons. Compos Struct 2013;98:323-9. doi:http://dx.doi.org/10.1016/j.compstruct.2012.10.040.

[32] Valluzzi MR, Valdemarca M, Modena C. Behavior of brick masonry vaults strengthened by FRP laminates. J Compos Constr 2001;5:163-9. doi:Doi 10.1061/(Asce)1090-0268(2001)5:3(163).

[33] Basilio I, Fedele R, Lourenço PB, Milani G. Assessment of curved FRP-reinforced masonry prisms: Experiments and modeling. Constr Build Mater 2014;51:492-505.

doi:http://dx.doi.org/10.1016/j.conbuildmat.2013.11.011.

[34] Fagone M, Rotunno T, Xhemali A. The adhesion between CFRP sheet reinforcements and masonry arches: an experimental analysis. In: Barros H, Ferreira C, Adam JM, Delatte N, editors. 2nd Int. Conf. Recent Adv. Nonlinear Model. - Des. Rehabil. Struct., Coimbra, Portugal: 2017.

[35] Grande E, Milani G. Modeling of FRP-strengthened curved masonry specimens and proposal of a simple design formula. Compos Struct 2016;158:281-90. doi:http://dx.doi.org/10.1016/j.compstruct.2016.09.017.

[36] Fagone M, Rotunno T, Briccoli Bati S. The Groin Vaults of St. John Hospital in Jerusalem: An Experimental Analysis on a Scale Model. Int J Archit Herit 2016;10:903-918. doi:10.1080/15583058.2016.1158331. 
Revised version highlighted: Green reviewer \#1, Yellow reviewer \#2

[37] Briccoli Bati S, Fagone M, Rotunno T. Lower Bound Limit Analysis of Masonry Arches with CFRP Reinforcements: A Numerical Method. J Compos Constr 2013;17:366. doi:10.1061/(asce)cc.19435614.0000350 .

[38] Cancelliere I, Imbimbo M, Sacco E. Experimental tests and numerical modeling of reinforced masonry arches. Eng Struct 2010;32:776-92. doi:10.1016/j.engstruct.2009.12.005.

[39] Lucchesi M, Pintucchi B, Zani N. Dynamic analysis of FRP-reinforced masonry arches via a notension model with damage. Key Eng Mater 2015;624:619-26.

doi:10.4028/www.scientific.net/KEM.624.619.

[40] European Standard. EN 998-2 Specification for mortar for masonry - Part 2: Masonry mortar 2016.

[41] ASTM C1583/C1583M-13. Standard Test Method for Tensile Strength of Concrete Surfaces and the Bond Strength or Tensile Strength of Concrete Repair and Overlay Materials by Direct Tension (Pulloff Method) 2013.

[42] MathWorks. Matlab 9.4.0 2018.

[43] Briccoli Bati S, Fagone M, Ranocchiai G. The effects of mortar joints on the efficiency of anchored CFRP sheets reinforcements of brick-masonry. Key Eng Mater 2015;624:575-83.

doi:10.4028/www.scientific.net/KEM.624.575. 